\title{
Evolution of Locomotor Trends in Extinct Terrestrial Giants Affected by Body Mass
}

\author{
Valery B. Kokshenev ${ }^{1}$ and Per Christiansen ${ }^{2}$ \\ ${ }^{1}$ Departamento de Física, Universidade Federal de Minas Gerais, Belo Horizonte \\ ${ }^{2}$ University of Aalborg, Department of Biotechnology, Chemistry, and Environmental \\ Engineering, Sohngaardsholmsvej 57, DK-9000 Aalborg \\ ${ }^{1}$ Brazil \\ ${ }^{2}$ Denmark
}

\section{Introduction}

It is generally accepted that bone morphology may be influenced by functional bone strains or stresses (McMahon, 1973, 1975a, b; Alexander, 1977; Bertram \& Biewener 1990, 1992; Biewener, 1990; Christiansen, 1999, 2002a, b). However, the problem as to which specific mechanical characteristics are most relevant remains open (e.g., Rubin \& Lanyon, 1984; Fritton et al., 2000; Biewener, 2000, 2005). Aiming to establish correlations between structural proportions and posture of mammalian limbs coping with body's locomotory functions, including support of mass in the gravitational field, scaling studies of limb long bones in terrestrial mammals have been subject to long standing debate and controversy (Biewener, 1982, 1983, 1989, 1990, 2000, 2005; Biewener et al., 1983; Biewener \& Taylor, 1986; Selker \& Carter, 1989; Bertram \& Biewener, 1990, 1992; Christiansen, 1997, 1998, 1999, 2002a, b, 2007; Fariña et al., 1997; Carrano, 1998, 1999, 2001; Currey, 2003; Kokshenev, 2003; Kokshenev et al., 2003). The exploration of basic concepts of stability of ideal and non-ideal solid cylinders loaded in non-critical, transient and near critical mechanical regimes, mapped to arbitrary loaded curved limb long bones, resulted in a number of mechanical patterns of similarity in long bones adjusted to their design (Kokshenev, 2007). Established under fairly general assumptions, the proposed scaling rules (for peak longitudinal-bone and transverse-bone elastic forces and momenta, compressive and shear strains, corresponding to axial and non-axial bending and torsional components of tensorial stress) congruent with bone allometry explained the two basic patterns of functional stresses in vivo revealed in the limb bones of fast running terrestrial mammals by Rubin \& Lanyon $(1982,1984)$.

The theoretically established patterns of bone design (Kokshenev, 2007) have been also tested (Kokshenev \& Christiansen, 2010) by the surprisingly varied differential scaling of the limb long bones in Asian (Elephas maximus) and African (Loxodonta africana) elephants. These terrestrial giants have more upright limb bones to vertical, notably much more upright propodials (humerus and femur), which are held at a distinctly greater angle compared to the ground than is the case in other large, quadrupedal mammals. Studies of their locomotor mechanics have also indicated differences from other terrestrial mammals, in that fast locomotion is ambling with no suspended phase in the stride, but with duty factors exceeding 0.5 (Alexander et al., 1979; Hutchinson et al., 2006). The theoretical predictions 
by Kokshenev (2007) were compared with data from a phylogenetically wide sample of proboscideans from Christiansen (2007). Consequently, some salient features distinguishing limb postures characteristic of locomotion in proboscideans and mammals were established. The limb bone allometry in Asian elephants and the Elephantidae was shown to be congruent with adaptation to bending-torsion proportions of stress induced by muscular forces, likewise in other mammals, whereas limb bones in African elephants appear adapted for coping with the dominating axial compressive forces of gravity. Since the hindlimb bones in extant and most likely extinct elephants were shown to be more compliant than forelimb bones, the limb compliance gradient of limb locomotory function, contrasting in sign to other mammals, was shown to constitute a new important dynamic constraint preventing elephants from achieving a full-body aerial phase in fast gaits of locomotion.

Considering the athletism of non-avian dinosaurs and adopting the assumption of dynamic similarity, Alexander (1976) analyzed inferred bending stress in their limb bones, which led him to the hypothesis (Alexander, 1981, 1985a) that animals appear to be built with universal (equal bodyweight-independent) limb safety factors (bone strengths related to corresponding peak bone stresses). However, systematic studies of functional limb bone stress by Rubin \& Lanyon $(1982,1984)$ clearly demonstrated that the dimensionless factor of limb safety may not be chosen as the determinant of dynamic similarity revealed across body mass through the speed and frequency in fast running bipeds and quadrupeds. Instead, a new kind of dynamic strain similarity (physically equivalent to dynamic stress similarity) observed in limb bones of walking, trotting, and galloping animals experimentally established by many researchers (Rubin \& Lanyon, 1982, 1984; Rubin \& Lanyon, 1982; Biewener et al., 1983; Biewener \& Taylor, 1986) has been only recently understood in light of more general mechanical elastic similarity (Kokshenev, 2007). It has been in particular demonstrated that the consistency between the elastic strain similarity by Rubin \& Lanyon $(1982,1984)$ and the elastic static stress similarity by McMahon (1975a) exists, since both are underlaid by the same patterns of elastic forces emerging in solids, that can be revealed if the external gravitational forces are substituted by predominating functional muscular forces (Kokshenev, 2003; Kokshenev et al., 2003). In this chapter, we try to establish a link between the mechanical elastic similarity in limb bones of different-sized animals (McMahon, 1973, 1975a, b; Rubin \& Lanyon, 1982, 1984; Kokshenev, 2003, 2007) and the seminal dynamic similarity in locomotion of animals (Alexander, 1976, 1989; Alexander \& Jayes, 1983), arising in turn from the more general mechanical similarity of uniform classical systems (Kokshenev, 2011a, b).

Following Schmidt-Neielsen (1984), it has been widely recognized that body mass is often a major locomotory factor scaling muscle force output establishing limits for body ability in animals (Alexander, 1985b; Hutchinson \& Garcia, 2002; Biewener, 2005, Hutchinson et al., 2005; Marden, 2005), through their maximal speed (Garland, 1983; Jones \& Lindstedt, 1993; Sellers \& Manning, 2007) and maximal size (Hokkanen, 1986a; Biewener, 1989; Kokshenev, 2007). Reconstructing body mass and locomotion in extinct animals (Alexander, 1989, 1991, 1998, 2006; Fariña \& Blanco, 1996; Fariña et al., 1997; Carrano, 1998; 2001; Carrano \& Biewener, 1999; Farlow et al., 2000; Wilson \& Carrano, 1999; Hutchinson \& Gatesy, 2006, Sellers \& Manning, 2007), the biomechanical modeling also includes their locomotor habits (e.g., Fariña, 1995; Paul \& Christiansen, 2000; Christiansen \& Paul 2001; Blanco \& Jones, 2005; Fariña et al., 2005). The evolutionary history of dinosaurs and mammals provide evidence for convergent similarities of skeletal design (e.g., near parasagittal limb postures and hinge-like joints), locomotor kinematics (Alexander, 1991, 1998; Farlow et al., 2000; Carrano, 1998, 1999; 2001; Paul \& Christiansen, 2000; Hutchinson et al., 2006), and 
biomechanics (see reviews by Hutchinson, 2006; and Alexander, 2006), as well as inferred physiology and growth rates (e.g., Ji et al., 1998; Horner et al., 1999; Rensberger \& Watabe, 2000; Sander, 2000; Erickson, 2004; Padian et al., 2004). However, locomotor complexity cannot be captured in a simple model since the number of required parameters increases rapidly as a model becomes more complex (Hutchinson \& Gatesy, 2006). One issue of great importance in biomechanics is therefore to more accurately employ generalizations following from dynamic similarity concepts suggested a few dimensionless universal (body mass independent) numbers (Alexander \& Jayes, 1983; Gatesy \& Biewener, 1991) or a few number of universal scaling (exponents in scaling) rules (Garland, 1983; Heglund \& Taylor, 1988; Biewener, 1990; Farley et al.,1993; Bejan \& Marden, 2006; Kokshenev, 2010), which potentially make a bridge between locomotory trends in large modern elephants, the largest extant, and the largest extinct proboscideans (e.g., Kokshenev \& Christiansen, 2010). Although the experimental exploration of dynamic similarity determinants was repeatedly questioned, e.g., in the context of dimensionless body safety factors (Biewener, 1982, 1990, 2000, 2005) or Froude numbers (Hutchinson et al., 2006), the empirical studies of locomotor evolution in extinct animals (e.g., archosaurs reviewed by Hutchinson, 2006) evidence for that evolution in running and turning abilities in extinct giants, accomplished by transformations in poses and postures of animals, expose a certain kind of adaptive similarity driven by body mass. Developing here the application of dynamic stress similarity generally supported by some available dynamic data on reconstructed extinct giants, we demonstrate how the empirically established traits of locomotory evolution in extinct terrestrial giants can be explained as affected by maximal body mass through limb-bone adaptations.

\section{Materials and methods}

\subsection{Materials}

\subsubsection{Maximal body mass}

The principal sources of data on maximal body masses $M_{\max }^{(\exp )}$ inferred from remains of some of the largest non-avian dinosaurs and mammals are listed in Table 1. Other published data are cited at appropriate points.

\subsubsection{Dynamic strain and stress similarities}

The in vivo studies by Rubin \& Lanyon $(1982,1984)$ on the individual-bone functional peak stress $\sigma_{\text {bone }}^{(\text {peak })}(M, V)$, resulted from gauge implantation in the long limb bones, revealed the dynamic stress (or strain) similarity in animals of different body mass $M$ running at a certain speed $V$. For the special studied case of biped and quadruped animals (from a turkey to an elephant) running at their fastest speeds $V_{\max }$, the corresponding pattern of dynamic stress similarity (shown below Table 2 in Rubin \& Lanyon, 1984) can be read here as

$$
\sigma_{\text {bone }}^{(\max )}\left(M, V_{\max }\right)=\sigma_{\text {axial }}^{(\exp )}(M)+\sigma_{\text {bend }}^{(\exp )}(M) .
$$

The axial and bending components of the compressive tibial stress where scaled to body mass (ranged from $7.3 \mathrm{~kg}$ to $2500 \mathrm{~kg}$ ) and analyzed by the least-squares liner regression method resulted in

$$
\sigma_{\text {axial }}^{(\exp )}(M)=C_{\text {axial }}^{(\exp )} M^{-0.05}, \text { with } \sigma_{\text {bend }}^{(\exp )}(M)=C_{\text {bend }}^{(\exp )} M^{0.08},
$$




\begin{tabular}{|l|l|c|l|c|}
\hline Taxon & Largest species & $M_{\max }^{(\exp )}, k g$ & References & $\beta_{d u t y}^{(\text {pred })}$ \\
\hline Dinosauria,Sauropoda, & Argentinosaurus & 70000 & Mazetta et al., 2004 & $>0.5$ \\
\hline Dinosauria, Sauropoda & Supersaurus & 38000 & Lovelace et al., 2007 & $>0.5$ \\
\hline Dinosauria, Sauropoda & Giraffatitan & 38000 & Taylor, 2009 & $>0.5$ \\
\hline Dinosauria, Theropoda & Giganotosaurus & 9000 & Mazetta et al., 2004 & $<0.5$ \\
\hline Dinosauria, Theropoda & Tyrannosaurus & 8000 & Mazetta et al., 2004 & $<0.5$ \\
\hline Dinosauria, Ornithopoda & Shantungosaurus & 16000 & Horner et al., 2004 & $<0.5$ \\
\hline Mammalia, Proboscidea & Mammuthus trogontherii & 20000 & Christiansen, 2004 & $\approx 0.5$ \\
\hline Mammalia, Proboscidea & Deinotherium giganteum & 18000 & Christiansen, 2004 & $\approx 0.5$ \\
\hline Mammalia, Perissodactyla & Indricotherium & 19000 & $\begin{array}{l}\text { Fortelius \& Kappe- } \\
\text { lmann, 1993 }\end{array}$ & $<0.5$ \\
\hline
\end{tabular}

Table 1. Some data on maximal body masses in terrestrial giants. The limb duty limb factor is provided as an expected characteristics indicating that animals could run with a suspended phase in the stride (with $\beta_{d u t y}<0.5$ ) or would able to progress with a walking gait only (with $\beta_{\text {duty }}>0.5$ ).

where

$$
C_{\text {axial }}^{(\exp )}=11 \mathrm{MPa} \cdot(\mathrm{kg})^{0.05} \text { and } C_{\text {bend }}^{(\exp )}=28 \mathrm{MPa} \cdot(\mathrm{kg})^{-0.08} .
$$

Testing the dynamic stress similarity hypothesis by Rubin \& Lanyon (1984), the continuous-speed dynamic similarity between different-sized animals, moving in a certain gait, was studied by Biewener \& Taylor (1986) through the gait-dependent individual-bone stress function $\sigma_{\text {bone }}^{(\max )}(M, V)$, also analyzed by Rubin \& Lanyon (1982). Experimental studies of the peak stress measured in the midshaft of long bones in fast walking, moderately running (or trotting) animals, and fast running (or galloping) animals with smoothly changing speed, resulted in that $\sigma_{\text {bone }}^{(\max )}(M, V)$ is a linear piecewise function of speed, which domains are limited by the gait-dependent "speed-equivalent" points $V_{\text {trans }}^{(\max )}$, as suggested by Biewener \& Taylor (1986).

When the allometric data from individual bones in running mammals are generalized to effective limb bone (e.g., Kokshenev, 2003), the corresponding peak functional stress is suggested here in the form

$$
\sigma_{\text {limb }}^{(\max )}(M, V)=\sigma_{\text {axial }}^{(\max )}(M)+\sigma_{\text {bend }}^{(\max )}(M) \frac{V}{V_{\text {trans }}^{(\max )}},
$$

where the transient speeds $V_{\text {trans }}^{(\max )}$ are characteristic points of the crossover-gait (walk-to-run) dynamic states or transient-mode (trot-to-gallop) dynamic states, discussed in the context of dynamic similarity theory (Kokshenev, 2011a, b). The reliably of the suggested gait-dependent pattern of dynamic stress similarity in an effective bone shown in Eq. (4) can be inferred from the in vivo compressive stress data exemplified by those from three walking, trotting, and galloping adult goats analyzed by Biewener \& Taylor (1986, Figs. 2B and 4), which generally unify the experimental data from the radius and tibia in a goat with those in a dog (Rubin \& Lanyon, 1982) and a horse (Rubin \& Lanyon, 1982; Biewener et al., 1983).

\subsubsection{Limb bone design}

Aiming to make a bridge between limb bone design in extant and extinct animals listed in Table 1, for which systematic data on the bone length $(L)$ and bone circumference $(C)$ as 


\begin{tabular}{|l||c|c|c||c|c|c||c|c|c|}
\hline \multicolumn{1}{|c|}{} & \multicolumn{4}{c||}{ Mammals } & \multicolumn{3}{|c||}{ Proboscidea } & \multicolumn{3}{|c|}{ Elephantidae } \\
\hline Limb bones & $N$ & $\lambda^{(\exp )}$ & $r$ & $N$ & $\lambda^{(\exp )}$ & $r$ & $N$ & $\lambda^{(\exp )}$ & $r$ \\
\hline Humerus & 189 & 0.7631 & 0.9738 & 16 & 1.134 & 0.831 & 7 & 0.912 & 0.990 \\
\hline Radius & 189 & 0.7530 & 0.9957 & 10 & 1.078 & 0.878 & 6 & 0.813 & 0.853 \\
\hline Ulna & 189 & 0.849 & 0.9600 & 14 & 0.929 & 0.866 & 6 & 0.727 & 0.888 \\
\hline Femur & 189 & 0.8431 & 0.9763 & 14 & 0.802 & 0.816 & 7 & 0.747 & 0.966 \\
\hline Tibia & 189 & 0.7641 & 0.9499 & 11 & 0.772 & 0.857 & 6 & 0.751 & 0.925 \\
\hline Limb bone & 189 & $\mathbf{0 . 7 9 5}$ & 0.971 & 13 & $\mathbf{0 . 9 4 3}$ & 0.850 & 6 & $\mathbf{0 . 7 9 0}$ & 0.924 \\
\hline
\end{tabular}

Table 2. Statistical data on the slenderness of individual and effective limb bones in animals reproduced from Table 1 in Kokshenev \& Christiansen (2010). The mean slenderness exponents are presented by the slopes $\lambda^{(\exp )}$ derived in $N$ species through the least-squares (LS) regression with the correlation coefficient $r$. The LS characterization of the effective limb bone corresponding to the overall-bone mean data is introduced as the standard mean of all data on five bones. The bold numbers are the data used below. The italic numbers indicate some the slope data contrasting to systematic mammalian data $\lambda_{(\operatorname{mam})}^{(\exp )}<1$.

functions of body mass are not available, the effective limb bone for extinct species can be introduced through the statistical data on the slenderness exponents $\lambda\left(=d \log _{10} L / d \log _{10} C\right)$ obtained regardless of the body mass data. Some employed below examples of extinct Mammalia are listed in Table 2.

\subsection{Theory}

\subsubsection{Stress similarity}

In fast gaits of locomotion, all types of elastic strains (and thus stresses), including axial uniform compressive strains, non-uniform tensile strains and transverse non-uniform shear strains, are generally involved in the hindlimbs of terrestrial animals. Considering the cases of the fastest speed dynamic regimes discussed in Eq. (1), we employ the principle of superposition for the simple axial, and complex bending and shear-strain (torsional) elastic fields, resulted in the total compressive stress

$$
\sigma_{\text {limb }}^{(\max )}\left(M, V_{\max }\right)=\alpha \sigma_{\text {axial }}^{(\max )}+\beta \sigma_{\text {bend }}^{(\max }+\tau \sigma_{\text {tors }}^{(\max )}, \text { with } \alpha+\beta+\tau=1,
$$

emerging in an effective limb bone. The peak stress appears as a combination of the partial functional axial, bending, and torsional stresses weighted respectively by relative probabilities $\alpha, \beta$, and $\tau$. These mass-independent probabilities play the role of indicators of the dynamic stress similarity, likewise the limb duty factors and swept angles discussed in the theory of dynamic similarity in animal locomotion (Kokshenev, 2011a, b).

Unlike the individual-bone data discussed in Eq. (1), we introduce an effective mammalian limb bone unifying six long bones (humerus, radius, ulna, femur, tibia, and fibula), through their geometric similarity determined by the bone-diameter and bone-length allometric exponents

$$
d_{\text {limb }}^{(\exp )}=0.36 \pm 0.02 \text { and } l_{\text {limb }}^{(\exp )}=0.28 \pm 0.02, \text { with } \lambda_{\text {limb }}^{(\text {pred })}=0.78 \pm 0.02
$$

established (Kokshenev, 2007, Table 1) via the LRS data from mostly running extant mammals (79 species, 98 specimens, Table 2 in Christiansen, 1999). One can see that the data on 
slenderness exponent $\lambda_{\text {limb }}^{(\text {pred })}=l_{\text {limb }}^{(\exp )} / d_{\text {limb }}^{(\exp )}$ shown in Eq. (6) match well those established from a wider spectrum of extant mammals (189 species, 612 specimens, see Table 3 below).

The theory of stress similarity, arising from the more general mechanical elastic similarity, provides three patterns of elastic similarity functional stresses discussed in Eq. (5), namely,

$$
\sigma_{\text {func }}^{(\max )}(M)=C_{\text {func }}^{(\max )} M^{\mu}
$$

establishing the stress similarity through the corresponding scaling exponents

$$
\mu_{\text {bend }}=\mu_{\text {tors }}=d-l \text {, with } d+l=\frac{2}{3} \text {, and } \mu_{\text {axial }}=-\frac{2}{3} \mu_{\text {bend }}
$$

in limbs of adult, or large species of different-sized animals (Kokshenev, 2007, Fig. 2). Leaving for a while the scaling parameters $C_{\text {func }}^{(\max )}$ in Eq. (7), requiring a special consideration beyond the scaling theory, we stress that the bone-diameter $d$ and the bone-length $l$ scaling exponents are also external parameters of the dynamic similarity theory.

When the most simplest isometric similarity $\left(d_{0}^{(i s o m)}=l_{0}^{(i s o m)}=1 / 3\right)$ is adopted for the limb design, evidently excluding bone curvature effects in bone stress (e.g., Bertram \& Biewener, 1992), the only one type of functional stress associated with the oversimplified body support function can be distinguished through the weight-independent isometrically universal stresses

$$
\sigma_{\text {bend }}^{(\text {isom })} \sim \sigma_{\text {tors }}^{(\text {isom })} \sim \sigma_{\text {axial }}^{(\text {isom })} \propto M^{0}
$$

straightforwardly following from Eqs. (7) and (8). In contrast, when the mammalian-limb realistic design discussed in Eq. (6) is adopted, the scaling rules for stress similarity functions determined by the scaling exponents

$$
\mu_{\text {bend }}^{(\text {pred })}=\mu_{\text {tors }}^{(\text {pred })}=0.08 \text { and } \mu_{\text {axial }}^{(\text {pred })}=-0.05
$$

become well theoretically observable through the axial-bone and bending-bone stress similarity discussed in Eq. (2). Thereby, it has been repeatedly demonstrated that the dynamic strain similarity experimentally established in limbs of fast running animals (Rubin \& Lanyon, 1982, 1984) is grounded by the mechanical elastic similarity established for effective limb bones (Kokshenev, 2007). In other words, we have shown that the effective limb bone from running mammals shown in Eq. (6) is designed as adapted to the primary locomotory functions, presented by the body mobility and support functions patterned in Eq. (10).

The experimental data by Rubin \& Lanyon (1982) for the axial and bending stress discussed in Eqs. (1) and (2) have been obtained at special experimental conditions of a special choice of the local-midshaft coordinate systems consequently excluding shear strains. In the context of the limb stress similarity suggested in Eqs. (5) and (7) these conditions are viewed as to be conventionally introduced by the two sets of stress indicators $(\alpha, \beta, \tau)$ presented by $(1,0,0)$ and $(0,1,0)$, respectively. Restoring the torsional stress $\sigma_{\text {tors }}^{(\max )}$ in all stress-similarity equations through the corresponding scaling exponent in Eq. (10), we also adopt in Eq. (5) the scaling factors

$$
C_{\text {bend }}^{(\max )}=C_{\text {tors }}^{(\max )}=C_{\text {mobil }}^{(\exp )}=27 \mathrm{MPa} \cdot(\mathrm{kg})^{-0.08} \text { and } C_{\text {axial }}^{(\max )}=C_{\text {supp }}^{(\exp )}=11 \mathrm{MPa} \cdot(k g)^{0.05} .
$$


When compared with Eq. (3), the experimental data $C_{\text {supp }}^{(\exp )}$ for the body support function is adopted without change, whereas the data for the body mobility function $C_{\text {mobil }}^{(\exp )}$ is slightly modified by the statistical analysis extended by in vitro data on the tibial failure in torsion (Kokshenev, 2007, Fig. 1).

\subsubsection{Critical body mass}

Taking into consideration that instead of the axial-bone stress the bending and torsional functional stresses limit the body mobility of animals involved in strenuous activity, the upper limit of body mass, or the critical body mass $M_{\max }^{(\text {crit })}$, follows from the relevant functional-stress constraint

$$
\sigma_{\text {mobil }}^{(\max )}(M)=C_{\text {mobil }}^{(\exp )} M^{0.08}=s_{\text {mobil }}^{(\max )}\left(\frac{M}{M_{\max }^{(c r i t)}}\right)^{0.08}, \operatorname{providing} M_{\max }^{(c r i t)}=\left(\frac{s_{\text {mobil }}^{(\max )}}{C_{\text {mobil }}^{(\exp )}}\right)^{\frac{1}{0.08}},
$$

introduced on the basis of Eqs. (5) and (10). Here $s_{\text {mobil }}^{(\max )}$ is the strength of the bone subjected to complex bending-torsion loading and $C_{\text {mobil }}^{(\text {exp })}$ is shown in Eq. (11).

The in vitro data on the mean individual-bone strength $s_{\text {funct }}^{(\text {mean })}$ are known for a compact long bones damaged under pure axial compression, i.e., $s_{\text {axial }}^{(\text {mean })} \approx 200 \mathrm{MPa}$ employed by Alexander (1981) and Biewener (1990), pure bending and torsion, i.e., $s_{\text {bend }}^{(\text {mean })} \approx 51 \mathrm{MPa}$ and $s_{\text {tors }}^{(\text {mean })} \approx 60 \mathrm{MPa}$ reported by Taylor et al. (2003). Given that generally the $\pm 10 \%$ domain is adopted for the statistically established mean bone strengths, the maximal amplitude data

$$
s_{\text {bend }}^{(\max )}=56.1 \mathrm{MPa}, s_{\text {tors }}^{(\max )}=66 \mathrm{MPa}, \text { and } s_{\text {axial }}^{(\max )}=220 \mathrm{MPa}
$$

result in limiting estimates for the critical masses (Kokshenev, 2007)

$$
M_{\text {bend }}^{(\text {crit })}=\left(\frac{s_{\text {bend }}^{(\max )}}{C_{\text {bend }}^{(\max )}}\right)^{\frac{1}{0.08}}=9.3 \text { tons and } M_{\text {tors }}^{(\text {crit })}=\left(\frac{s_{\text {tors }}^{(\max )}}{C_{\text {tors }}^{(\max )}}\right)^{\frac{1}{0.08}}=71 \text { tons. }
$$

These two critical body masses determine two kinds of similarity patterns of well distinct body postures in giants, whose body mobility is supposedly limited by critical pure bending and pure torsional stresses emerging in their limbs at maximal speeds of critical locomotion. Using empirical data in Table 1, the patterns of most erect posture and most sprawling posture in giants, may be respectively presented by the obligate biped Giganotosaurus, likely capable for relatively fast running and the largest terrestrial quadruped Argentinosaurus, an animal so huge that a true run would likely have severely injured the limb bones via critical torsional stresses. Indeed, sauropod anatomy speaks vehemently against anything other than a walk gait anyway.

\subsubsection{Body safety}

Bearing in mind that the limb safety during strenuous activity of terrestrial animals establishes the risk level of skeleton damage (Alexander, 1981; Biewener, 1982, 1989, 1990), a generalized 
body-skeleton safety function $S_{\text {body }}(M, V)$ based on the additivity of functional stresses $\sigma_{\text {funct }}^{(\max }(M, V)$ could be suggested as

$$
S_{\text {body }}(M, V)=\left(\sum_{\text {functions }} \frac{\sigma_{\text {funct }}^{(\max )}(M, V)}{s_{\text {funct }}^{(\max )}}\right)^{-1}
$$

The dynamic stress similarity experimentally and theoretically represented in, respectively, Eqs. (1), (4), (11) and (5), (7), (8), suggests the following piecewise functional form, namely

$$
S_{\text {body }}^{-1}(M, V)=\frac{\alpha}{s_{\text {axial }}^{(\max )}} C_{\text {supp }}^{(\exp )} M^{\mu_{\text {axial }}}+\left(\frac{\beta}{s_{\text {bend }}^{(\max )}}+\frac{\tau}{s_{\text {tors }}^{(\max )}}\right) C_{\text {mobil }}^{(\exp )} M^{\mu_{\text {bend }}} \frac{V}{V_{\max }}, \text { with } S_{\text {body }} \geq 2,
$$

for the body safety function activated in slow (walk) and fast (walk and run) gaits of animals moving within a certain speed domain limited by $V_{\max }$. The shown domain (analyzed in Figs. 1 and 3 in Kokshenev, 2007) conventionally establishes a condition for realization of the mechanically equilibrated, non-critical dynamic similarity states in slow and moderately fast gaits of locomotion, as exemplified by the non-critical axial stress (Kokshenev, 2007, Table 2, Eq. (2)).

Coming back to the problem of the maximal mass of terrestrial giants mentioned in the Introduction, a question arises whether the body support function may establish the critical body mass $M_{\text {body }}^{(\text {crit })}$ determined by critical-point condition $S_{\text {body }}^{(\text {crit })}\left(M_{\text {body }}^{(\text {crit })}, V_{\max }\right)=1$, which in fact violate the domain of validation shown in Eq. (16)? Searching for the answer, let analyze the relevant model solution $M_{b o d y}^{(c r i t)}(\alpha, \beta, \tau)$ provided by

$$
\frac{\alpha}{s_{\text {axial }}^{(\max )}} C_{\text {supp }}^{(\exp )} M_{\text {body }}^{\mu_{\text {axial }}}+\left(\frac{\beta}{s_{\text {bend }}^{(\max )}}+\frac{\tau}{s_{\text {tors }}^{(\max )}}\right) C_{\text {mobil }}^{(\exp )} M_{\text {body }}^{\mu_{\text {bend }}}=1, \text { with } \alpha+\beta+\tau=1,
$$

following from Eq. (16). In Eq. (14), the two particular solutions $M_{\text {body }}^{(\text {crit })}(0,1,0)=9.3$ tons and $M_{b o d y}^{(\text {crit })}(0,0,1)=71$ tons were discussed as critical masses attributed, respectively, to the largest theropod and the largest sauropod, obtained in the effective limb-bone approximation (shown in Eqs. (10) and (11)). One can see that the obtained limiting masses introduce the validation domain for the body mobility function in giants, namely

$$
S_{\text {mobil }}(M, V)=\left(\frac{M_{\max }^{(\text {crit })}}{M}\right)^{\mu_{\text {bend }}} \frac{V_{\max }}{V} \text {, with } S_{\text {mobil }} \geq 1 .
$$

The critical mass discussed in Eq. (12) is now specified by

$$
M_{\max }^{(\text {crit })}(\beta)=\left(\frac{C_{\text {mobil }}^{(\exp )-1} s_{\text {bend }}^{(\max )} s_{\text {tors }}^{(\max )}}{\beta s_{\text {tors }}^{(\max )}+\tau s_{\text {bend }}^{(\max )}}\right)^{\mu_{\text {bend }}^{-1}}, \text { with } \tau=1-\beta,
$$


as follows from Eq. (16) taken at the critical condition $S_{\text {mobil }}^{(\text {crit })}\left(M, V_{\max }\right)=1$, with $\alpha=0$.

The domain shown in Eq. (18) for the body mobility function conventionally indicates the condition for realization of the near-critical transient states of continuous dynamic similarity, associated with locally equilibrated universal transformations of near-critical compressive strains into non-critical global shear strains, eventually decreasing the resulted compressive bone stress (Kokshenev, 2007).

\section{Results}

Several aspects concerning the problem of evolution of locomotory trends in extinct animals are discussed in view of generalizations suggested by the dynamic stress similarity approach.

\subsection{Critical mass}

In order to establish the role of competing axial, bending, and torsional stresses in the problem of the maximal mass of terrestrial giants, we analyze the domains of observation of the corresponding probabilities $\alpha, \beta$, and $\tau$ through Eq. (17) where the critical mass $M_{b o d y}^{(c r i t)}(\alpha, \beta, \tau)$ is associated with maximal body mass $M_{\max }^{(\exp )}$ known for the largest giants (Table 1). Since in most cases of bone specimens for extinct species the allometric exponents $d$ and $l$ are not available, we employ statistical data on the slenderness exponent $\lambda^{(\exp )}$ for the effective limb bone (Table 2). Instead of Eq. (10), the theoretical predictions for the scaling exponents in Eq. (17) are estimated through

$$
\mu_{\text {axial }}^{(\text {pred })}=-\frac{4}{9} \frac{1-\lambda}{1+\lambda} \text { and } \mu_{\text {bend }}^{(\text {pred })}=\mu_{\text {tors }}^{(\text {pred })}=\frac{2}{3} \frac{1-\lambda}{1+\lambda}
$$

established with the help of the definitive equation for the exponent $\lambda=l / d$ excluding $d$ and $l$ from those shown in Eq. (8). Allowing the whole domains for all kinds of stresses to be exploited by giants during near-critical locomotion, e.g., for bending stress $0 \leq \beta \leq 1$, hereafter designated as [0;1], the resulted observable domains are shown in Table 3.

Fig. 1 illustrates the analysis in Table 3 indicating domains of exploration of the axial, bending and torsional stresses by limb bones in the largest mammalian species running or walking at the critical condition $S_{b o d y}^{(c r i t)}=1$. The semi-qualitative analysis ${ }^{1}$ indicates that neither maximal critical mass nor maximal near-critical mass of terrestrial giants is affected by axial stress. In other words, instead of body safety function lying beyond the critical locomotion domain, as shown in Eq. (16), the body mobility function establishes the critical behavior (see Fig. 2) determined by the critical mass

$$
M_{\text {mobil }}^{(\text {crit })}(\beta)=\left[\frac{137.1}{(1-\beta) 56.1+\beta 66}\right]^{\frac{1}{0.08}}, \text { with } 0 \leq \beta \leq 1,
$$

represented from Eq. (19) in the mammalian limb-bone approximation discussed in Eq. (6).

$$
M_{\text {mobil }}^{(\text {crit })}(\beta)=\left[\frac{137.1}{(1-\beta) 56.1+\beta 66}\right]^{\frac{1}{0.08}}, \text { with } 0 \leq \beta \leq 1,
$$

\footnotetext{
${ }^{1}$ The provided analysis is treated as semi-qualitative since, unlike the scaling exponents (Table 3 ), the data on the scaling factors, discussed in Eq. (10), are still taken in the mammalian-limb approximation.
} 


\begin{tabular}{|l|l|c|c|c|c|c|c|c|}
\hline Largest giants in & \multicolumn{1}{|c|}{$N, n$} & $\lambda^{(\mathrm{exp})}$ & $\mu_{\text {axial }}^{(\text {pred }}$ & $\mu_{\text {bend }}^{(\text {pred }}$ & $M_{\max }^{(\mathrm{exp})}, \mathrm{kg}$ & $\alpha$ & $\tau$ & $\beta$ \\
\hline Mammals & $N=189$ & 0.795 & -0.051 & 0.076 & 20000 & {$[0 ; 0.03]$} & {$[0.85 ; 0]$} & {$[0.15 ; 0.97]$} \\
\hline Proboscidean & $N=13$ & 0.943 & -0.013 & 0.020 & 20000 & n.e.s. & {$[1 ; 0.95]$} & {$[0.95 ; 1]$} \\
\hline Elephantidae & $N=6$ & 0.790 & -0.520 & 0.078 & 20000 & n.e.s. & {$[1 ; 0.30]$} & {$[0.40 ; 1]$} \\
\hline Asian elephant & $n=106$ & 0.851 & -0.036 & 0.054 & 8000 & n.e.s. & {$[1 ; 0.35]$} & {$[0.45 ; 1]$} \\
\hline African elephant & $n=56$ & 0.648 & -0.094 & 0.141 & 10000 & {$[0.35 ; 0.45]$} & {$[0.65 ; 0]$} & {$[0 ; 0.55]$} \\
\hline
\end{tabular}

Table 3. Maximal body mass and limb bone design determine the stress-similarity domains through the corresponding stress indicators. The domains of the axial $(\alpha)$, bending $(\beta)$, and torsion $(\tau)$ stresses explored by the body safety function (shown in squared brackets) are obtained through Eq. (17) where the scaling exponents $\mu_{\text {axial }}^{(\text {pred })}$ and $\mu_{\text {bend }}^{(\text {pred })}=\mu_{\text {tors }}^{(\text {pred })}$ are estimated through Eq. (20). The data on the critical mass $M_{\max }^{(\exp )}$ for Mammuthus trogontherii is used for the largest taxon in both Mammalia, Proboscidea, and Elephantidae (Table 1). The largest masses for extant Asian (Elephas maximus) and African (Loxodonta africana) elephants are for exceptionally large bulls (Wood, 1976; Nowak, 1991; McFarlan, 1992; Blashford-Snell \& Lenska, 1996). The LS regression data on the slenderness exponents $\lambda^{(\exp )}$ of long bones from $N$ species are taken from Table 2 and from $n$ specimens for elephants are taken from Table 2 in Kokshenev \& Christiansen (2010). Notation: n.e.s. - not employing stress.

\begin{tabular}{|c|c|c|c|c|c|c|}
\hline Dynamic conditions & \multicolumn{2}{|c|}{ Optimum speed } & \multicolumn{2}{|c|}{ Maximum power } & \multicolumn{2}{|c|}{ Near critical regime } \\
\hline Locomotory muscle type & slow & fast & slow & fast & slow & fast \\
\hline Contraction frequency & $L_{m}^{-1}$ & $L_{m}^{-1 / 2}$ & $L_{m}^{-3 / 2}$ & $L_{m}^{-1}$ & $L_{m}^{-2}$ & $L_{m}^{-3 / 2}$ \\
\hline Contraction velocity & $L_{m}^{0}$ & $L_{m}^{1 / 2}$ & $L_{m}^{-1 / 2}$ & $L_{m}^{0}$ & $L_{m}^{-1}$ & $L_{m}^{-1 / 2}$ \\
\hline
\end{tabular}

Table 4. Dynamic characterization of the slow and fast striated muscles (of resting length $L_{m}$ ) contracting at optimum-speed (maximum-efficiency), maximum-speed (maximum-power), and near critical (low-safety) dynamic conditions (reproduced from Table 4 in Kokshenev, 2009).

represented from Eq. (19) in the mammalian limb-bone approximation discussed in Eq. (6). In Fig. 3 we extend the analysis of locomotory trends in Fig. 2 to other large giants, modeled by near critical safety factors lying in narrow domain $1.0<S_{\text {mobil }} \leq 1.1$, corresponding to the $10 \%$ domain established for the mean bone strengths, as discussed in Eq. (13).

\subsection{Froude numbers}

Modeling the animal locomotion by contractions of locomotory muscles activated at natural frequencies, the data on optimal speeds $V_{\text {opt }}^{(\exp )} \sim M^{1 / 6}$ of bipeds (Gatesy\& Biewener, 1991) and quadrupeds (Heglund \& Taylor, 1988) running in fast locomotor modes can be explained by activation of the fast locomotor muscles of length, linearly scaling with limb length (or hip height) $L_{b}^{(\text {isom })} \sim M^{1 / 3}$ (Kokshenev, 2009, 2010) presented in the isometric-similarity approximation discussed in Eq. (9). Modeling the low-safety locomotion of large giants by critical-velocity muscle contractions (see Table 4), let us adopt the scaling relations $V_{\text {walk }}^{(\mathrm{mod})} \sim$ $L_{b}^{-1}$ and $V_{\text {run }}^{(\text {mod })} \propto L_{b}^{-1 / 2}$ for critically walking or running giants moving due to activation of slow and fast limb muscles, respectively. 


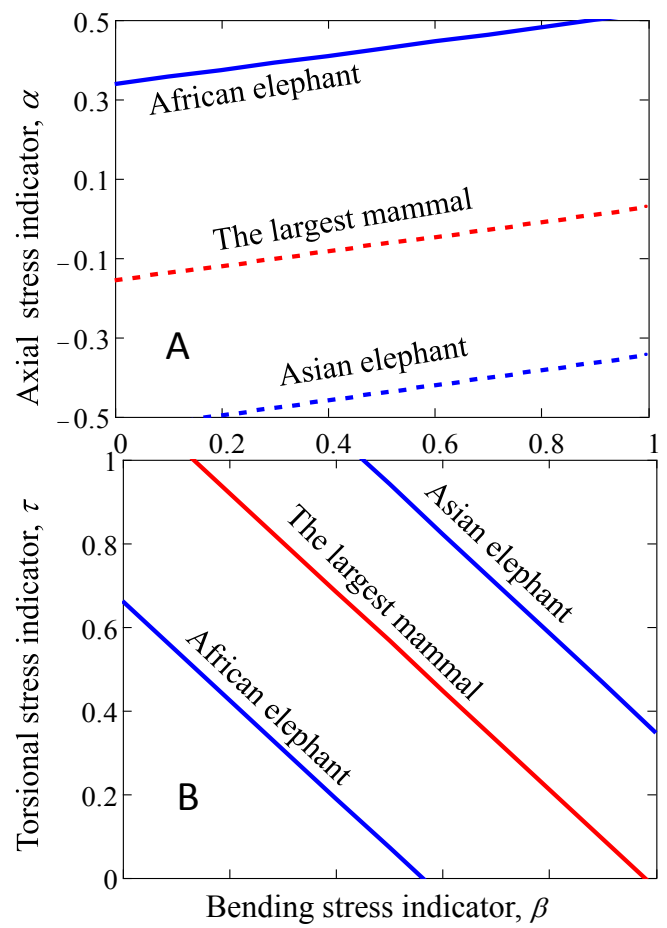

Fig. 1. The comparative role of limb adaptation in the largest mammal and elephant (extinct species) through the elastic reaction to muscle loading forces (via turning-bending stress, Fig. 1A) and ground-reaction forces (mostly via axial stress, Fig. 1B). The solid and dashed lines correspond to employing and non-employing domains (Table 3).

Choosing the model critical-state Froude number $\left(F r_{\text {critic }}^{(\mathrm{mod})}=V_{\text {crit }}^{2} / g L_{b}\right.$, where $g$ is the gravitational field) as a relative squared-speed characteristics of animal locomotion (Alexander \& Jayes, 1983; Gatesy\& Biewener, 1991), one obtains the scaling relations $F r_{\text {walk }}^{(\text {mod })} \sim L_{b}^{-3}$ and $\mathrm{Fr}_{\text {run }}^{(\text {mod })} \sim L_{b}^{-2}$, adopted for model Froude numbers in the simplest isometric geometry approximation $L_{b}^{(\text {isom })} \sim L_{m}^{(i s o m)} \sim M_{\max }^{1 / 3}(\beta)$. Hence, one obtaines the critical-mass scaling rules $F r_{\text {walk }}^{(\mathrm{mod})} \sim M_{\max }^{-1}(\beta)$ and $F r_{\text {run }}^{(\bmod )} \sim M_{\max }^{-2 / 3}(\beta)$ distinguishing dynamic similarities in a walk and a run gaits in giants, moving in the near critical mobility regime. When the walk-to-run continuous transition, in vivo established for modern elephants by Hutchinson et al. (2006) at Froude numbers $F r_{w-r}^{(\exp )} \approx 1$ and duty factors $\beta_{d u t y}^{(\exp )} \approx 0.5$ is mapped onto the walk-to-run crossover in evolution of trends in extinct largest giants indicated by transient bending-torsion stress similarity at $\beta=0.5$, the model similarity scaling equations for near critical level of walking and running quadrupedal giants are suggested as

$$
F r_{\text {walk }}^{(\text {quadr })}=24.7 M_{\max }^{-1}(\beta) \text { and } F r_{\text {run }}^{(\text {quadr })}=8.48 M_{\max }^{-2 / 3}(\beta),
$$

(here critical mass is taken in tons) with the help of Eq.(22). 


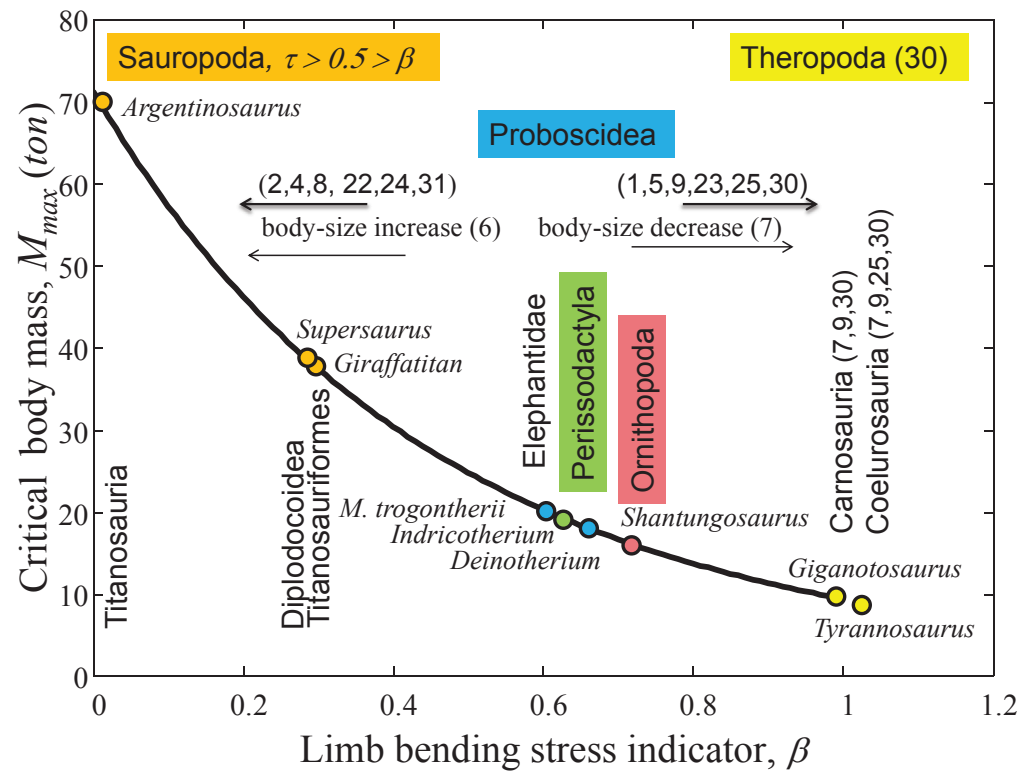

Fig. 2. Analysis of locomotor evolution of the largest terrestrial giants scaled by the limb bending parameter. The solid line is critical mass drawn by Eq. (22). The points correspond to giants in Table 1 . The arrows indicate the biomechanical trends described by competitive empirically revealed traits (Hutchinson, 2006, Table 1): (1), more erect posture; (2), less erect posture; (4), quadrupedalism; (5), striding bipedalism; (6), body-size increase; (7), body-size decrease; (8), more upright pose; (9), more crouched pose; (22), poor bipedal running ability; (23), good bipedal running ability; (24), poor turning ability; (25); improved turning ability; (30), more cursorial limb proportions; (31), less cursorial limb proportions.

\subsection{Turning and bending mobilities}

Being remarkably similar, both limb-bone longitudinal bending elastic force $F_{\text {bend }}$ and transverse torsion force $F_{\text {tors }}$ scale with body mass as $M^{3 d-l}$, within the domain of similar dynamic states including transient near-critical states (Kokshenev, 2007, Eq. (17), Table 2). The force scaling equations, taken in the mammalian limb-bone approximation, i.e., with $3 d-l=1.20$, are completed by the scaling factors approximated by muscle-reaction forces from the largest 6-ton Tyrannosaurus modeled by Hutchinson et al. (2007). ${ }^{2}$ Treating the total force exerted by leg muscles over the center of body mass as the vectorial sum of vertical and horizontal forces, resulted in the total muscle force output, the corresponding skeletal body reaction force, limiting body mobility is found as the root mean square of the corresponding elastic forces emerging in the effective limb bones, i.e., $F_{\text {mobil }}^{(\mathrm{mod})}=\left(F_{\text {bend }}^{(\mathrm{mod}) 2}+F_{\text {tors }}^{(\bmod ) 2}\right)^{1 / 2}$. When extrapolated to other largest extinct giants, the relative forces provide the model estimates,

\footnotetext{
${ }^{2}$ Specifically, for the case of $F_{\text {tors }}$ we employ the data (Hutchinson et al., 2007, Table 6, Model 3) on maximal (medial and lateral) rotation muscle moments and moment arms of turning force exerted about center of mass of the trunk. The case of $F_{b e n d}^{(\mathrm{mod})}$ is adjusted with the maximal vertical ground reaction force that the limb could support (Hutchinson et al., 2007, Table 9, Model 23).
} 


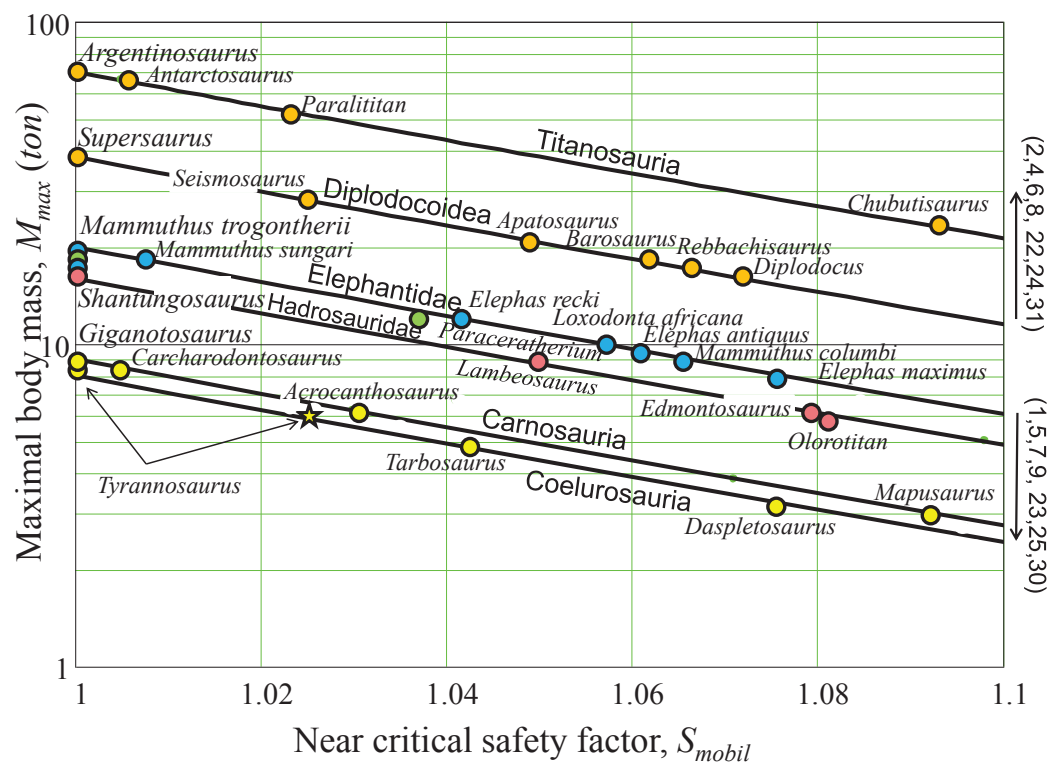

Fig. 3. Maximal body masses for terrestrial giants modeled by the near-critical locomotor behavior. Solid lines are drawn by Eq.(18) taken at maximal stride speeds. The points are data from Table 1 and other available sources. The star corresponds to 6-ton modeled Tyrannosaurus (Hutchinson et al., 2007; Sellers \& Manning, 2007).

namely

$$
\frac{F_{\text {tors }}^{(\mathrm{mod})}}{M g}=0.87 \cdot M^{-0.20}, \frac{F_{\text {bend }}^{(\mathrm{mod})}}{M g}=1.89 \cdot M^{-0.20}, \frac{F_{\text {mobil }}^{(\mathrm{mod})}}{M g}=2.08 \cdot M^{-0.20}, \text { with } S_{\text {mobil }} \geq 1,
$$

discussed in Fig. 5.

\section{Discussion}

Our study develops Alexander's hypothesis on that the locomotor dynamic similarity in non-avian dinosaurs can be inferred from the bending stress in their limbs (Alexander, 1976). We have demonstrated how the knowledge on elastic stress (or strain) similarity reliably established in limbs of different-sized running mammals may provide rationalizations of locomotory trials empirically suggested for extinct terrestrial giants. Allowing the generalized mammalian limb bone to be arbitrary loaded, the body functions of giants of different taxa subjected to cyclic loading during locomotor activity are viewed in terms of a few dynamic similarity patters provided by elastic theory of solids. Our theoretical study suggests that even though the dynamic similarity is underlaid by a certain set of elastic force patterns, there are several ways in which they may be realized and thus described.

The elastic patterns of forces emerging in the effective mammalian limb bone loaded in distinct (globally equilibrated non-critical stationary states and near-critical transient states 


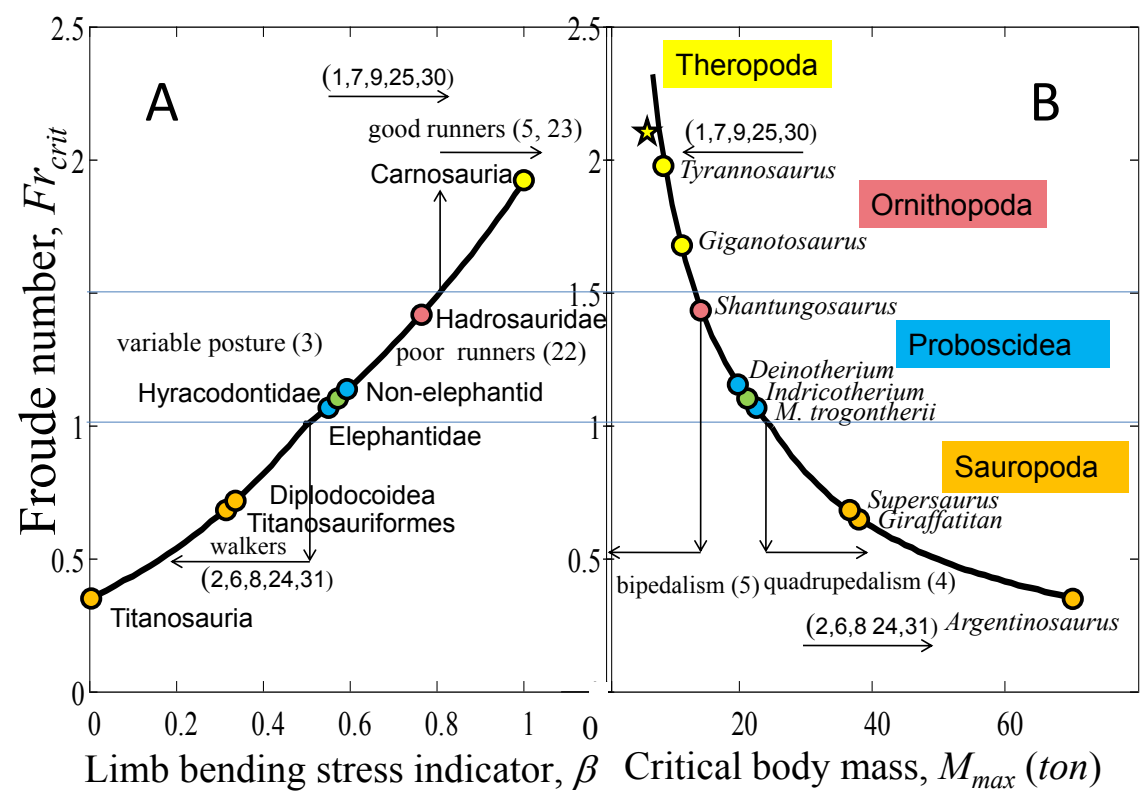

Fig. 4. Froude numbers expected from the largest terrestrial giants during near-critical locomotion. The solid curves are drawn through Eqs. (23) and Eq. (22); The points (Table 1) and notations for taxa and traits correspond to those in Fig. 1. The star shows the experimental data $F r_{\text {run }}^{(\exp )}=2.1$ for the fast running 6-ton Tyrannosaurus modeled by Sellers \& Manning (2007).

of ) dynamic similarity regimes (Kokshenev, 2007) have been revealed earlier through the bone design observed in different-sized animals through the allometric data on linear bone dimensions (Kokshenev et al., 2003; Kokshenev, 2007) and slenderness (Kokshenev, 2003; Kokshenev \& Christiansen, 2010). All theoretical studies of the data were critically discussed within the context of McMahon's pioneering criteria of elastic similarity (McMahon, 1973, 1975a, b). The observation of elastic force patterns through the locomotory functions evaluated on the basis of available data on the maximal masses of extinct giants is one of the objectives of the presented approach. The critical-state similarity regime is treated as theoretically established if the observable characteristics are shown to be driven by one of the predominating critical-force patterns.

Even though animals are built from the same bone tissue and muscle tissue materials, the safety factors of limbs in running animals are not universally equal (Kokshenev, 2007, Fig. 3), as was suggested by earlier estimates (Alexander, 1981, 1985a) of the isolated dynamic stress states and systematical observations of limb safety factors (Biewener, 1982, 1983, 1989, 1990, $2000,2005)$. On the other hand, in non-critical dynamic regimes of locomotion the body safety function discussed in Eq. (16) could also conventionally be observed, either theoretically or experimentally, as "almost" universal. The first kind of observations could be made through 


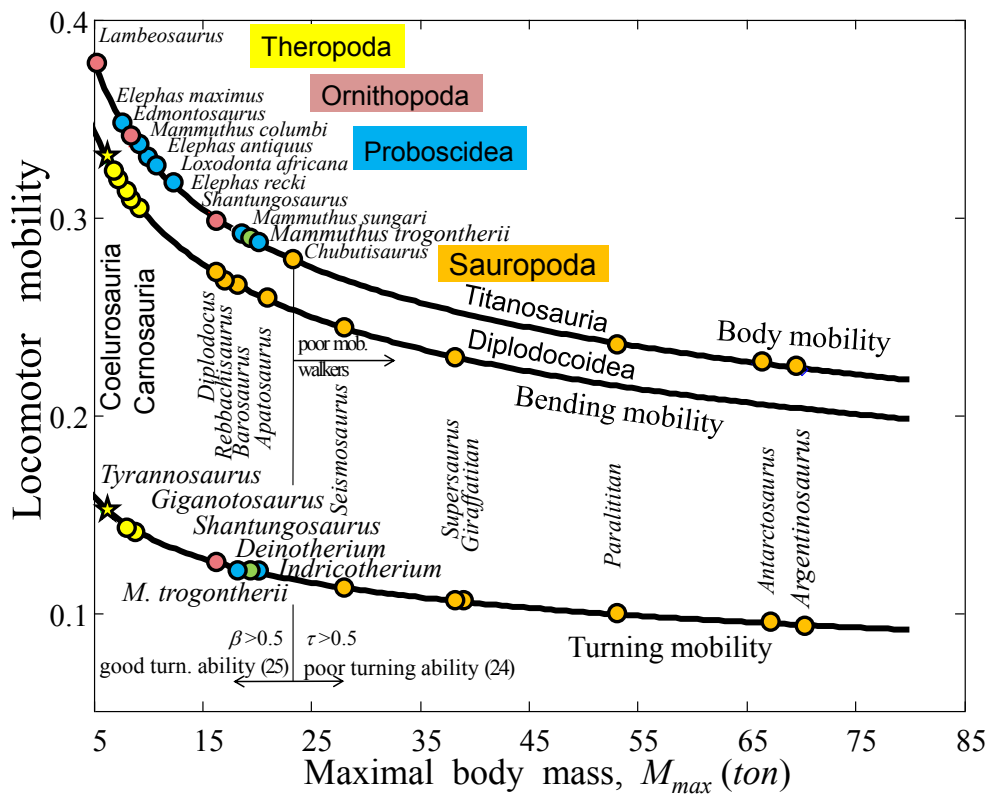

Fig. 5. Locomotor mobilities expected for extinct giants. The curves for relative limb bone elastic forces are drawn via Eq. (24) and notations correspond to Figs. 2 and 4. The stars are the data on 3D Tyrannosaurus experimentally modeled by Hutchinson et al. (2007).

the corresponding oversimplified bending stress estimated under assumption of the almost isometric mammalian bones, as shown in Eq. (9). In this case we have ignored small by finite scaling bone-mass effects (Prange et al., 1979), which significance in limb bone allometry has previously been discussed (Kokshenev et al., 2003) and statistically evaluated (Kokshenev, 2007). In the second case, the desirable observation of the seemingly universal functional limb stress implies that the safety factor domain reliably established in running mammals as lying between 2 and 4 should indicate almost invariable safety function approximated by the number $3 \pm 1$. In the current research, the dynamic similarity features in giants moving in near-critical dynamic regimes are revealed through the stress-similarity indicators of the underlying patterns of axial, bending and torsional elastic forces. As is common in dynamic similarity theories, the patterns of scaling rules and related dimensionless numbers (Kokshenev, 2011a) or functions (Kokshenev, 2011b) determine the conditions of observation of dynamic similarity states.

Our recent study of similarities and dissimilarities in locomotory trends of extant and extinct proboscideans, indicated by the slenderness characteristics of design of the effective limb bones (Kokshenev \& Christiansen, 2010), has revealed new features of their locomotory functions. The Asian elephants (E. maximus) are dynamically similar to the family Elephantidae and have been found to be distinct from the African elephants (L. africana). Moreover, the Elephantidae as group including both kinds of extant elephants, clearly exposed a negative limb duty gradient (with respect to other mammals, Fig. 6) in the body mobility function, closely related to the proximal-distal gradient (Biewener et al., 2006) in body ability function. Qualitatively, the hind-to-fore gradient in limb locomotor activity 


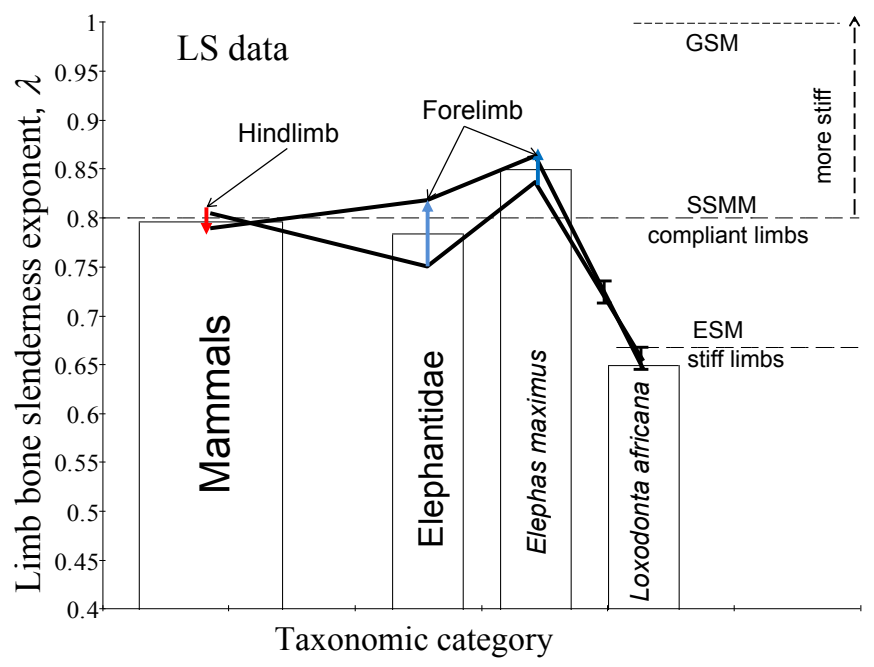

Fig. 6. The observation of elastic similarity across different taxa via bone slenderness exponents (Table 2) for the effective forelimb bone (humerus, radius, and ulna) and hindlimb bone (femur and tibia). The arrows indicate deviations in the trends of adaptation of forelimb and hindlimb bones associated with gradients in the corresponding mechanical functions. The bar shows statistical error. Notations: GSM and ESM indicate the predictions of the geometric similarity model and elastic similarity model of McMahon (1973, 1975a); SSMM indicates the static stress similarity model (McMahon, 1975a, SSM) modified by muscle forces (Kokshenev, 2003). For further details, see Fig. 4 in Kokshenev \& Christiansen (2010).

caused by the difference in bone proportions of hind and fore limbs (Fig. 6, mammals ) explains the differing postures in mammals as group as well as elephants (Kokshenev \& Christiansen, 2010, Fig. 5). The negative gradient of limb functions for the Elephantidae (including the extant species, but mainly comprising of extinct species) suggests a trend for forelimbs to be designed more isometrically, and also for the forelimbs of E. maximus to be mechanically stiffer than the hindlimbs. The newly established dynamic constraint, contrasting in sign to that of other mammals and mechanically extending the hindlimb ground contact duration, explains why elephants are prevented from achieving a full-body aerial phase during fast gaits of locomotion.

The design remarkably observed (Table 6) for the effective limb bone in the African elephant (5 limb bones, 56 specimens, Table 3 ) is surprisingly similar to that established in adult ungulates (5 limb bones, 118 specimens, McMahon, 1975b) mostly from the family Bovidae (see also analysis by Selker \& Carter, 1989). The distinct from other effective bones, say, pillar-type limb bone, is statistically established via the slenderness exponent $\lambda^{(\exp )} \approx \lambda_{0}^{(E S M)}=2 / 3$ predicted by the elastic similarity model (ESM, Fig. 6). The pillar-like limb bone pattern underlaid by the critical buckling force (McMahon, 1973, 1975a) is well distinguished from the mammalian-type limb bone, determined experimentally in Eq. (6) and predicted by SSMM through $\lambda_{0}^{(S S M M)}=7 / 9$ (Kokshenev \& Christiansen, 2010, footnote 1). The buckling force was introduced in the theory of elasticity of solids by Euler as the critical axial elastic force 
provoking critical bending deformations under loading conditions of the absence of non-axial external forces (e.g., Kokshenev et al., 2003; Kokshenev, 2003). McMahon therefore proposed that terrestrial animals would optimize their skeleton support function so that were similarly in danger of elastic mechanical failure by buckling under gravity (e.g., Christiansen, 1999). The corresponding to buckling mechanism loading, the simplest model for terrestrial giants, as an animal standing on one leg and subjected to increasing with weight gravitational force, was proposed by Hokkanen (1986a). Although it has been clearly demonstrated that the maximal body mass of terrestrial giants is not limited by axial critical forces, associated with buckling mechanism of damage of naturally curved bones (e.g., Currey, 1967; Hokkanen, 1986a, b; Selker \& Carter, 1989), the corresponding scaling pattern of the Euler's force (e.g., Kokshenev et al., 2003, Eq. (1)) emerging under aforesaid dynamic conditions may survive and even predominate at loads far from critical. Moreover, as one may infer from the reliable observation of the effective pillar-type bone, the pattern of critical buckling force most likely controls the limb elastic stress of animals, in which limb muscles function as to resist non-axial external forces, through the proximal-distal functional gradients, evolutionary resulting in the limb bone design mostly adapted to the axial-bone peak loading. Hence, when one considers competitive patterns of functional elastic stresses in a certain effective bone of unknown design, as discussed on general basis in Eq. (5), equally with the term of non-critical axial stress $\sigma_{\text {axial }}^{(\max )}$, which negative allometry $\left(\mu_{\text {axial }}<0\right)$ was predicted by $\sigma_{\text {axial }}^{(\text {pred })} \propto M^{2 / 3-2 d}$ (Kokshenev, 2007, Eq. (5), Table 3), one should not exclude the possibility of axial stress predicted as $\sigma_{\text {axial }}^{(E S M)} \propto M^{2(d-l)}$ (Kokshenev et al. 2003, Eq. (4)) underlying the pattern of pillar-type bones.

Following the ESM (Fig. 6), the individual limb bones in L. africana are mostly influenced by gravitational and ground reaction forces, generating buckling-type dynamic elastic stress of the peak amplitude $\sigma_{\text {axial }}^{(E S M)}$. This finding is supported by our study of the competing functional axial, bending and torsional stresses occurring in the limbs of the largest extinct giants at similar critical states modeled by the maximal body masses of Asian and African elephants, Elephantidae, and mammals as whole (Table 3, Fig. 1). Unlike the case of Asian elephants and running mammals, the axial predominating stress becomes observable through the maximal body mass of African elephants (Fig. 1A). As follows from Fig. 6, more reliable observation of the stress similarity in African elephants, as well as bovids (McMahon, 1975b), might be obtained when the scaling exponents $\mu_{\text {axial }}^{(\text {pred })}=-0.05$ and $\mu_{\text {bend }}^{(\text {pred })}=0.08$ in Eq. (16) are substituted by $\mu_{\text {Oaxial }}^{(E S M)}=1 / 4$ and $\mu_{0 b e n d}^{(E S M)}=1 / 8$, predicted by McMahon's elastic similarity model. Since the exponent for critical axial stress is expected to be twice as high as that for critical bending stress, we have thereby shown that in near-critical dynamic regimes the buckling force effects appear to dominate over bending-torsional force effects. Since the effective pillar-type limb bones, scaled to body mass as $\lambda_{0}^{(E S M)}=2 / 3$, are not ideal long cylinders, the critical (yield-state) bending strains (Kokshenev et al., 2003; Eq. (4)) dynamically transform into transient-state pure bending elastic strains (Kokshenev, 2007; Eq. (15)), as has been explained earlier by Currey (1967).

The analysis of elastic peak forces developed in ideal solid cylinders indicated that various conditions of application of external loads affect solely scaling factors, leaving unchanged scaling exponents determining elastic force patterns (e.g., Kokshenev et al., 2003, Eq. (1)) employed above in rationalization of the functional stress in Eq. (5) when applied to extinct animals. Unlike ideal cylinders, the individual long skeletal bones are mostly curved along the 
longitudinal axis in all but the largest extant mammals (Bertram \& Biewener, 1988, 1992), and even in the largest, elephant-sized theropod dinosaurs (e.g., Farlow et al., 1995; Christiansen, 1998). Hence, external loads produce a complex non-axial compression in long bones, causing different components (axial and non-axial) of reactive (elastic) bending and torsional stresses. Moreover, since the bone cross section is also not an ideal circle, near maximal bending stress can be avoided via the transient non-critical dynamic regimes by deviation of the bone from the sagittal plane, thereby decreasing bending stress through torsional stress (Kokshenev, 2007). Switching from bending deformation to out-off-plane torsion, such a mechanism reduces the risk of limb damage, naturally increasing bone safety factors. In this study, the stress in the non-uniformly loaded limbs of animals is modeled by an arbitrary composition of axial, bending, and torsional stresses, as shown in Eq. (5).

Unlike the case of the ESM underlaid by Euler's force, no explicit bending force pattern for McMahon's static stress similarity model (SSM, McMahon, 1975a) was established. Instead, in the in vitro experimental studies of long bone strength the critical transverse-bone force has been discussed as the perpendicular bending force that a bone can withstand without breaking (e.g., Hokkanen, 1986b, Eq. (11)) under either three-point or cantilever loading (Selker \& Carter, 1989; Eq. (4)). In spite of that it was widely adopted that most fractures in limbs of living animals are due to longitudinal-bone and transverse-bone torsional forces (e.g., Carter et al., 1980; Rubin \& Lanyon, 1982; Biewener et al., 1983; Biewener \& Taylor, 1986; Selker \& Carter, 1989) such generalizations resulting in transverse-bending, longitudinal-bending, and transverse-torsional elastic force patterns unified by the SSM have recently been established and tested (Kokshenev, 2007, Eq. (17) and Table 3). In this study, we have repeatedly demonstrated in Eq. (10) that the dynamic elastic stress similarity patterns (Kokshenev, 2007, Eq. (15)) can be observed through the effective (mammalian) limb bone design, which appears to be common to both extant and extinct large animals (Fig. 6). It is well established that the peak muscle contractions involved in locomotion are primarily responsible for bending and torsional stresses in bones (Carter et al., 1980; Biewener, 1982). Consequently, the definitive scaling equations of the SSM of long bones (McMahon, 1975a), completely ignoring predominating muscular forces, required a modification as indicated by the bone stress index (Selker \& Carter, 1989; Table 2). When experimentally indicated modifications have been provided through the gravitational forces substituted by external bending and torsional muscle's forces, the modified McMahon's model (SSMM) had turned to be reliable, i.e., observable through the bone allometry data from extant mammals (Kokshenev et al., 2003, Fig. 1, dashed area 2; Kokshenev, 2003, Fig. 2) and extinct animals (Fig. 6, SSMM). According to the SSMM, in the Elephantidae and in particular in E. maximus, the external bone off-axial muscular forces, causing a complex bending-torsion elastic bone stress during fast locomotion, provide a relatively high level of limb compliance conducted by the limb bones. These qualitative SSMM predictions are well supported by the analysis illustrated in Fig. 1B. Asian elephants are involved in torsional effects with the probability $(0.35 \leq \tau \leq 1)$ that on average is twice as high as that $(0 \leq \tau \leq 0.65)$ of the largest extant African elephants (Table 3$)$. Relatively large domains of exploration of bending-torsional stress, completely excluding the axial stress domain common to mammals, Proboscideans and Elephantidae (Table 3). These distinct dynamically features of limb bone functions accomplished by different predominating critical stresses result in distinct bone designs, as illustrated by the running-mammal and pillar-like effective limb bones.

In Fig. 2, the maximal masses of some extinct giants, from the largest theropod (9-ton Giganotosaurus and 8-ton Tyrannosaurus) to the largest sauropod (70-ton Argentinosaurus), are 
scaled by the bending stress set up in the limbs of animals moving at critically low limb safety factors. Our analysis, indicating probabilities of bending $(\beta)$ and torsional $(\tau)$ limb stresses as seen in various maximal body masses, is expected to establish a bridge between body size traits 6 and 7 and other biomechanical traits established for dinosaurs and reviewed by Hutchinson (2006). The anatomical data from bipedal (trait 5) theropods (long legs, long tibia relative to femur, long metatarsus, and very large limb muscles) suggest that they had well developed anatomical adaptations for running modes, as shown through the expected duty factor in Table 1. These generally agree with the observation in Fig. 2 of Sauropoda in, say, run-mode domain $\beta>0.5>\tau$ (we recall that $\tau=1-\beta$ ) indicated by limbs adapted for peak bending effects rather than peak torsional effects. Anatomy leaves no doubt whatsoever that all sauropods (trait 4) were capable of progression with a walking gait only, which generally determines the walk-mode domain $\tau>0.5>\beta$. The established trends linked to locomotor characterization of the limbs of giants, developing with body mass (trait 6) are supported by changes in competing biomechanical traits: from striding bipedalism (trait 5), related to good bipedal running ability (trait 23) to quadrupedalism (trait 4) through decreasing bipedal running ability (22). Likewise, the trend of changes in posture, pose, and limb proportions with body mass (varying from corresponding traits 1,9 , and 30 to traits 2, 8, and 31) could also be elucidated through the limb stress indicators. ${ }^{3}$ A crossover between giants found in run-mode and walk-mode domains during the evolution of competitive locomotory traits is indicated by the transient indicators $\tau \approx \beta \approx 0.5$, corresponding approximately to the Elephantidae (Fig. 2), whose limbs are expected to be biomechanically adapted to the transient (walk-to-run) dynamic similarity states.

In Fig. 3, the analysis of locomotor traits from Fig. 2 for the largest extinct giants is extended to smaller giants, belonging to the same anatomical type and large-scale taxon (e.g., family, order). When the critical (and near-critical) body mass criterion of the similarity in evolution of locomotory trends is adopted, the largest representatives of the taxa Titanosauria, Diplodocoidea, Titanosauriformes, Elephantidae, non-elephantid, proboscideans (a paraphyletic group of morphologically comparable taxa), Perissodactyla, Hadrosauridae, Carnosauria, and Coelurosauria are treated as locomotory patterns of similarity presented by biomechanically similar animals having limbs adaptively designed to explore the bending and torsion stresses in the strict narrow domains indicated (Fig. 2) by the corresponding probabilities $\beta$ and $\tau$. For example, the dynamic similarity pattern of Mammuthus trogontherii (Fig. 2) is now extended by the Elephantidae, including the largest extant 10-ton African and 8-ton Asian elephants (Fig. 3). Being analyzed by the body safety function in Eq. (16), where $\tau \neq 1-\beta$, these two compared elephants also differ in the mean stress indicators $\tau_{\text {African }}^{(\text {mean })} \approx \beta_{\text {African }}^{(\text {mean })}<0.5$, for African elephant, and $\tau_{\text {Asian }}^{(\text {mean })} \approx \beta_{\text {Asian }}^{(\text {mean })}>0.5$, for Asian elephant (Table 3, Fig. 1B). These different limb bone traits imply that even though both elephants generally fall into the transient walk-to-run evolutionary domain indicated by $\tau_{\text {eleph }}^{(\text {mean })} \approx \beta_{\text {eleph }}^{(\text {mean })}$, Asian elephants, showing $\beta_{\text {Asian }}^{(\text {mean })}>0.5$, reminiscent of running mammals rather than walking animals. In contrast, African elephants fall into the domain of walkers indicated by $\beta_{\text {African }}^{(\text {mean })}<0.5$.

\footnotetext{
${ }^{3}$ In this context, the set of traits $(6,8,31)$ suggested for the Carnosauria by Hutchinson et al. (2006) should be likely substituted by the set $(7,9,30)$, if this group is indeed characteristic of the non-avian Theropoda as whole.
} 
The top-speed dynamic regimes, broadly related to maximal body mobility, should not be expected for large animals (Garland, 1983; Christiansen, 2002b) especially if they move at near critical conditions. Within the framework of the current approach to critical locomotion, the top speed of the fastest land mammal, the cheetah (Sharp, 1997), conventionally separating small and large fast-running animals (Jones \& Lindstedt, 1993) and possibly determining a crossover in mammalian scaling trends of the appendicular skeleton (Christiansen, 1999), corresponds to the non-critical domain of body safety function discussed in Eq. (16) and the data $S_{\text {mobil }}=3 / 2$ (Kokshenev, 2007) for the body mobility function discussed in Eq. (18).

The non-critical linear dynamic similarity as seen in optimal locomotion by stride speeds $V_{\text {opt }}^{(\mathrm{mod})} \sim M^{1 / 6}$ and natural frequencies $T_{\text {opt }}^{(\exp )-1} \sim M^{1 / 6}$ in running bipeds (Gatesy \& Biewener, 1991) and trotting and galloping quadrupeds (Heglund \& Taylor, 1988; Farley et al., 1993) can be explained by the optimal-speed regime of muscle activation shown in Table 4. As such, dynamic similarity was shown (Kokshenev, 2009, 2010, 2011a) to be determined by minimum mechanical muscle action controlled during contractions by the condition of linear dynamic-length changes with muscle length $L_{m}$ (Table 4). The non-critical bilinear dynamic regime (maximum-power regime, Table 4) was proven to be responsible for muscle design adaptation to the primary locomotory functions (Kokshenev, 2008), whereas the higher non-linear regime of contraction of fast and slow muscles is associated here with near critical loading dynamic conditions $\left(1<S_{\text {mobil }} \leq 1.1\right.$, Fig. 3) resulting in model speeds $V_{\text {walk }}^{(\mathrm{mod})} \sim$ $M_{\text {max }}^{-1 / 3}$ and $V_{\text {run }}^{(\bmod )} \sim M_{\text {max }}^{-1 / 6}$, which follow from Table 4 . When the near critical regime speeds are compared with maximal speeds (limited by $2 \mathrm{~m} / \mathrm{s}$ for large quadrupedal sauropods and by $4 \mathrm{~m} / \mathrm{s}$ for bipedal dinosaurs) obtained by Tulborn (1990) using graphs of relative stride length against Froude number (Alexander, 1976), the estimates $V_{\text {walk }}^{(\mathrm{mod})}=8.3 M_{\text {max }}^{-1 / 3}$ and $V_{\text {run }}^{(\text {mod) }}=8.1 M_{\text {max }}^{-1 / 6}$ (masses are taken in tons) for the relatively slow-walking Argentinosaurus and slow-running Giganotosaurus (Table 1) are suggested. However, these estimates do not corroborate the idea of a continuos-speed evolution in gaits during a crossover from striding bipedalism (trait 5) to quadrupedalism (trait 4), as generally expected near the crossover-gait duty factor of around one half (Table 1) at a transient critical mass of around 25 tons (Fig. 2). Indeed, the estimates suggested for speeds within the scenario of a one-step continuous transition are not consistent, since they do not match when taken at the transient critical mass. We therefore propose a two-step scenario for evolution of locomotory functions: from (i) good bipedal running ability (trait 23), via (ii) decreasing bipedal running ability (trait 22), to (iii) quadrupedalism (trait 4).

Instead of speeds, the study of locomotor dynamic similarity in different-sized animals through Froude numbers is more appropriate (Alexander, 1976; Alexander \& Jayes, 1983, Gatesy \& Biewener, 1991). Most mammals appear to change their gait from walking to running discontinuously (abruptly) at a duty factor close to one half and Froude numbers below one (Ahlborn \& Blake, 2002; Alexander \& Jayes, 1983, Gatesy \& Biewener, 1991). Extant elephants, however, exhibit a continuous walk-to-run transition at magnitudes $\operatorname{Fr}_{w-r}^{(\exp )} \approx 1$ (Hutchinson et al., 2006; for comparative analysis of quadrupeds see Kokshenev, 2011b, Fig. 1). Mapping this transient-state similarity point onto the transient critical mass discussed in the context of similarity in locomotor evolution in extinct giants, Eq. (23) describes the crossover from striding bipedalism (trait 5) to quadrupedalism (trait 4). Then, when introducing the two-step evolution scenario via locomotor traits $23 \rightarrow 22 \rightarrow 24$ (Fig. 4) in the run-mode domain $(0.5<\beta \leq 1)$, we determine two locomotory patterns: (i) good 
runners capable of showing relatively high numbers $F r_{\text {run }}^{(\mathrm{mod})}>1.5$, since they have limbs mostly subjected to and, thus, adapted to near-critical bending stress of the domain, say, $0.8 \lesssim \beta<1$, and (ii) poor runners attributed to Froude numbers lying in the transient-state domain $1<F r_{w-r}^{(\mathrm{mod})} \leq 1.5$ and using moderate bending and moderate torsional stress indicated by $0.5<\beta \lesssim 0.8$. The walk-mode domain $(0<\beta \leq 0.5)$ establishes the locomotory pattern of (iii) walkers, for which $F r_{\text {walk }}^{(\mathrm{mod})} \leq 1$ is generally expected. The suggested scenario of evolution in giants of gait-dependent Froude function $\operatorname{Fr}(M)$ is found to be in good agreement with the data $F r_{\text {Tyrus }}^{(\exp )}=2.10$ (shown by star in Fig. 4B) for the experimentally modeled 6-ton Tyrannosaurus showing relatively high running speed $8 \mathrm{~m} / \mathrm{s}$ (Sellers \& Manning, 2007). One may also expect that more reliable estimates for critical speeds discussed above could be derived from the predicted Froude numbers (Fig. 4B) by re-scaling method.

It generally follows from Fig. 4 that with increasing body mass the evolution of locomotory patterns from good runners through poor runners to walkers is controlled by decreasing bending stress and increasing torsional elastic stress in the limbs. Based on the corresponding indicators $\beta$ and $\tau$, we are broadly able to characterize the accompanied evolution in postures and limb proportions, changing in striding running bipeds from (i) erect posture (trait 1) and more cursorial limbs (trait 30) to (iii) sprawling, or less erect posture (trait 2) and less cursorial limb proportions (trait 31), attributed to quadrupeds. The intermediate biped-to-quadruped locomotory evolution indicated by near equal proportions of moderate bending and torsional stress in limbs, may roughly be approached by elephantid and non-elephantid proboscideans, having rather short and compact bodies and fairly long limbs; these animals were undoubtedly not fast running with a suspended phase and therefore are found (Fig. 4) to be poor runners (trait 22). The largest land animal, Argentinosaurus, certainly could not run at all, but grouping in the walk-mode domain, it may be broadly regarded as having been a good walker.

While locomotor ability is provided by the relative body force output, body mobility is generally associated with the corresponding reaction-body elastic force, provided in most part by limb bone elastic forces. The evolution of body mobility, resulting from turning and bending limb mobilities, moderately decreasing with body mass (Fig. 5), is concomitant with a suggested evolution from striding bipedalism (trait 5) to quadrupedalism (trait 4). The walking and running mobilities are distinguished through the walk-mode and run-mode domains of the bone-stress similarity indicators. The animals considered by Hutchinson (2006) to possess good running abilities (trait 23) as well as improved turning abilities (trait 25) are presented (Figs. 4 and 5) by a single pattern of good runners, which relatively high mobility is due to bending effects exceeding torsional effects in the limb bones. The animals characterized by poor turning ability (trait 24) and poor bending ability are treated as walkers constrained by relatively high-level torsional elastic stress developed in long bones.

As can be inferred from Fig. 5, smaller quadrupedal giants from the Proboscidea, poorly running elephants at relatively high safety factors, may expose the same body mobility as the slow running largest bipedal giants of the Theropoda, operating close to critical levels. The body mobility of extinct elephants, moving at near critical levels, e.g., presented by Deinotherium giganteum (Fig. 5), is one-fourth of that of running African and Asiatic elephants (Kokshenev, 2011b, Fig. 2). 


\section{Conclusion}

We hope to have shown how a simple theoretical treatment of the similarities in the peak functional stress reliably established for the effective mammalian limb bone may provide new generalizations in the evolution with body mass of locomotory trends in extinct terrestrial giants, accompanied by evolution in postures and limb proportions affected by maximal body mass through limb-bone adaptations to primary locomotor body functions.

\section{Acknowledgments}

One of the authors (V.B.K.) acknowledges financial support by the national agency FAPEMIG.

\section{References}

Ahlborn, B.K. \& Blake, R.W. (2002). Walking and running at resonance, Zoology 105:165-174. Alexander,R.McN. (1976). Estimates of speeds of dinosaurs, Nature 261: 129-130.

Alexander, R. McN. (1977). Allometry of the limbs of antelopes (Bovidae), Journal of Zoology 183: $125-146$.

Alexander, R.McN. (1981). Factors of safety in the structure of animals, Science Progress Oxford 67: 109-130.

Alexander, R. McN. (1985a). Mechanisms of posture and gait of some large dinosaurs, Zoological Journal of Linnean Society 83:1-25.

Alexander, R. McN. (1985b). The maximum forces exerted by animals, Journal of Experimental Biology 115: 231-238.

Alexander, RMcN. (1989). Optimization and gaits in the locomotion of vertebrates, Physiological Review 69: 1199-1227.

Alexander, R.McN. (1991). Doubts and assumptions on dinosaurs mechanics, Interdisciplinary Scientific Review 16: 175-1981.

Alexander, R. McN. (1998). All-time giants: The largest animals and their problems, Paleontology 41: 1231-1245.

Alexander, R.McN. (2006). Dinosaur biomechanics, Proceedings of Royal Society B, 273: 1949-1855.

Alexander, R.McN. \& Jayes, A.S. (1983). A dynamic similarity hypothesis for the gaits of quadrupedal mammals, Journal of Zoology (London)201: 135-152.

Barriel, V., Thuet, E. \& Tassy, P. (1999). Molecular phylogeny of Elephantidae. Extreme divergence of the extant forest African elephant, Comptes Rendus de L'Academie des Sciences (Ser. III) 322: 447454.

Bertram, J.E.A. \& Biewener, A.A. (1988). Bone curvature: Sacrificing strength for load predictability? Journal of Theoretical Biology 131: 75-92.

Bertram, J.E.A. \& Biewener, A.A. (1990). Differential scaling of the long bones in the terrestrial Carnivora and other mammals, Journal of Morphology 204: 157-169.

Bertram, J.E.A. \& Biewener, A.A. (1992). Allometry and curvature in the long bones of quadrupedal mammals. Journal of Zoology 226: 455-467.

Biewener, A.A. (1982). Bone strength in small mammals and bipedal birds: do safety factors change with body size? Journal of Experimental Biology 98: 289-301.

Biewener, A.A. (1983). Allometry of quadrupedal locomotion: the scaling of duty factor, bone curvature, and limb orientation to body size, Journal of Experimental Biology 105: 147-171. 
Biewener, AA. (1989). Mammalian terrestrial locomotion and size. Mechanical design principles define limits, Bioscience 3: 776-783.

Biewener, A.A. (1990). Biomechanics of mammalian terrestrial locomotion, Science 250: 1097-1103.

Biewener, A.A. (2000). Scaling of terrestrial support: differing solutions to mechanical constraints of size, in Scaling in Biology of editors Brown, J. H. and West, G. B., Oxford University Press, Oxford, pp. 51-66.

Biewener, A.A. (2005). Biomechanical consequences of scaling, Journal of Experimental Biology 208: $1665-1676$.

Biewener, A.A., Thomason, J. \& Lanyon, L.E. (1983). Mechanics of locomotion and jumping in the forelimb the of the horse (Equus): in vivo stress developed in the radius and metacarpus Journal of Zoology 201: 67-82.

Biewener, A. \& Taylor, C.R. (1986). Bone strain: a determinant of gait and speed?, Journal of Experimental Biology 1235: 383-400.

Blanco, R.E. \& Jones, W.W. (2005). Terror birds on the run: A mechanical model to estimate its maximum running speed, Proceedings of the Royal Society of London 272: 1769-1773.

Blashford-Snell J. \& Lenska, R. (1996). Mammoth hunt, in Search for the Giant Eephants of Bardia, Harper-Collins, London.

Carrano, M.T. (1998). Locomotion in non-avian dinosaurs: integrating data from hindlimb kinematics, in vivo strains, and bone morphology, Paleobiology 24: 450-469.

Carrano, M.T. (1999). What, if anything, is a cursor? Categories versus continua for determining locomotor habit in mammals and dinosaurs, Journal of Zoology 247: 29-42.

Carter, D.R., Smith, D.J., Spengler, D.M., Daly, C.H. \& Frankel, V.H. (1980). Measurements and analysis on in vivo bone strains on the canine radius and ulna, Journal of Biomechanics 13: 27-38.

Carrano, M.T. (2001). Implications of limb bone scaling, curvature and eccentricity in mammals and non-avian dinosaurs, Journal of Zoology 254: 41-55.

Carrano, M.T. \& Biewener, A.A. (1999). Experimental alteration of limb posture in the chicken (Gallus gallus) and its bearing on the use of birds as analogs for dinosaur locomotion, Journal of Morphology 240: 237-249.

Christiansen, P. (1997). Locomotion in sauropod dinosaurs, GAIA 14: 45-75.

Christiansen, P. (1998). Strength indicator values of theropod long bones, with comments on limb proportions and cursorial potential, GAIA 15: 241-255.

Christiansen, P. (1999). Scaling of the limb long bones to body mass in terrestrial mammals, Journal of Morphology 239: 167-190.

Christiansen, P. (2002a). Mass allometry of the appendicular skeleton in terrestrial mammals, Journal of Morphology 251: 195-209.

Christiansen, P. (2002b). Locomotion in terrestrial mammals: the influence of body mass, limb length and bone proportions on speed, Zoological Journal of the Linnean Society 136: 685-714.

Christiansen, P. (2004). Body size in proboscideans, with notes on elephant metabolism, Zoological Journal of the Linnean Society 140: 523-549.

Christiansen, P. (2007). Long-bone geometry in columnar-limbed animals: allometry of the proboscidean appendicular skeleton, Zoological Journal of the Linnean Society 149: 423-436.

Christiansen, P. \& Paul, G.S. (2001). Limb bone scaling, limb proportions, and bone strength in neoceratopsian dinosaurs, GAIA 16: 13-29. 
Currey, J.D. (1967). The failure of exoskeletons and endoskeletons, Journal of Morphology 123: $1-16$.

Currey, J.D. (2003). The many adaptations of bone, Journal of Biomechanics 36: 1487-1495.

Erickson, G.M., Makovicky, P.J., Currie, P.J., Norell, M.A.,Yerby, S.A. \& Brochu, C.A. (2004): Gigantism and comparative life-history parameters of tyrannosaurid dinosaurs, Nature 430: 772-775.

Fariña, R.A. (1995). Limb bone strength and habits in large glyptodonts, Lethaia 28: 189-196.

Fariña, R.A., Blanco, R.E. \& Christiansen, P. (2005). Swerving as the escape strategy of Macrauchenia patachonica Owen (Mammalia; Litopterna), AMEGHINIANA (Review of Association of Paleontologists in Argentina) 42: 751-760.

Fariña, R.A. \& Blanco, R.E. (1996). Megatherium, the stabber, Proceedings of the Royal Society of London (Series B) 263: 1725-1729.

Fariña, R.A., Vizcaino, S.F. \& Blanco, R.E. (1997). Scaling of the indicator of athletic capability in fossil and extant land tetrapods, Journal of Theoretical Biology 185: 441-446.

Farley, J.R., Glasheen, J. \& McMahon, T. A. (1993). Running springs: speed and animal size, Journal of Experimental Biology 185: 71-86.

Farlow, J.O., Smith, M.B. \& Robinson, J.M. (1995). Body mass, bone "strength indicator", and cursorial potential of Tyrannosaurus rex, Journal of Vertebrate Paleontology 15: 713-725.

Fortelius, M. \& Kappelman, J. (1993). The largest land mammal ever imagined,Zoological Journal of the Linnean Society 107 (1): 85-101.

Fritton, S.P., McLeod, K.J. \& Rubin, C.T., (2000). Quantifying the strain history of bone: spatial uniformity and self-similarity of low magnitude strains, Journal of Biomechanics 33: 317-325.

Gambaryan, P.P. (1974). How Mammals Run. John Wiley \& Sons, New York.

Garland, T. (1983). The relation between maximal running speed and body mass in terrestrial mammals, Journal of Zoology 199: 157-170.

Gatesy, S.M. \& Biewener, A.A. (1991). Bipedal locomotion: effects of speed, size and limb posture in birds and humans, Journal of Zoology 224: 127-147.

Gatesy, S.M., Holtz, Jr.T.R., Hutchinson, J.R., \& Robinson, J.M. (2000). Theropod locomotion, American Zoology 40: 640-663.

Heglund, N.C., McMahon, T.A. \& Taylor, C.R. (1974). Scaling stride frequency and gait to animal size: mice to horses Science 186: 1112-1113.

Heglund, N.C. \& Cavagna, G.A. (1985). Efficiency of vertebrate locomotory muscles, Journal of Experimental Biology 115: 283-292.

Heglund, N.C. \& Taylor, C.R. (1988). Speed, stride, frequency and energy cost per stride: how do they change with body mass and gait?, Journal of Experimental Biology 138: 301-318.

Hokkanen, J.E.I. (1986a). The size of the largest land animal, Journal of Theoretical Biology 118: 491-499.

Hokkanen, J.E.I. (1986b). Notes concerning elastic similarity, Journal of Theoretical Biology 120: 499-4501.

Horner, J.R., Ricqles, A.J. de \& Padian, K. (1999). Long bone histology of the hadrosaurid dinosaur Maiasaura peeblesorum: Growth dynamics and physiology based on an ontogenetic series of skeletal elements, Journal of Vertebrate Paleontology 20: 115-129.

Horner, J.R., Weishampel, D.B. \& Forster, C. A. (2004). Hadrosauridae, in The Dinosauria, editors Weishampel, D.B., Dodson, P. and Osmólska, H. Berkeley, University of California Press. pp. 438-463.

Howell, A.B. (1944). Speed in Animals. Their Specialization for Running and Leaping. University of Chicago Press, Chicago. 
Hutchinson, J.R., 2006. The evolution of locomotion in archosaurs, Comptes Rendus Palevol 5: 519-530.

Hutchinson, J.R. \& Garcia, M. (2002). Tyrannosaurus was not a fast runner, Nature 415: 1018 $-1021$.

Hutchinson, J.R. \& Gatesy, S.M. (2006). Beyond the bones, Nature 440: 292-294.

Hutchinson, J.R., Anderson, F.C., Blemker, S.S. \& Delp, S.L. (2005). Analysis of hindlimb muscle moment arms in Tyrannosaurus rex using a three-dimensional musculoskeletal computer model: implications for stance, gait, and speed, Paleobiology 31: 676-701.

Hutchinson, J.R., Schwerda, D., Famini, D.J., Dale, R.H.I., Fischer, M.S. \& Kram, R. (2006). The locomotor kinematics of Asian and African elephants: changes with speed and size, Journal of Experimental Biology 209: 3812-3827.

Hutchinson, J.R, Ng-Thow-Hing, V. \& Anderson, F.A. (2007). A 3D interactive method for estimating body segmental parameters in animals: Application to the turning and running performance of Tyrannosaurus rex, Journal of Theoretical Biology 246: 660-680.

Ji, Q., Currie, P.J., Norell, M.A. \& Ji, S.-A. (1998). Two feathered dinosaurs from northeastern China, Nature 393: 753-761.

Jones, J.H. \& Lindstedt, S.L. (1993). Limits to maximal performance, Annual Review Physiology 55: 547-569.

Kokshenev, V.B. (2003). Observation of mammalian similarity through allometric scaling laws, Physica A 322: 491-505.

Kokshenev, V.B. (2007). New insights into long-bone biomechanics: Are limb safety factors invariable across mammalian species?, Journal of Biomechanics 40: 2911-2918.

Kokshenev, V.B. (2008). A force-similarity model of the activated muscle is able to predict primary locomotor functions, Journal of Biomechanics 41: 912-915.

Kokshenev, V.B. (2009). Scaling functional patterns of skeletal and cardiac muscles: New non-linear elasticity approach, arXiv:0909.1444v1.

Kokshenev, V.B. (2010). Key principle of the efficient running, swimming, and flying, Europhysics Letters 90: 48005.

Kokshenev, V.B. (2011a). Physical insights into dynamic similarity in animal locomotion. I. Theoretical principles and concepts, In: Theoretical Biomechanics, Vaclav Klika (ed.), pp. 267-284, ISBN 978-953-307-851-9

Kokshenev, V.B. (2011b). Physical insights into dynamic similarity in animal locomotion. II. Observation of continuous similarity states, In: Theoretical Biomechanics, Vaclav Klika (ed.), pp. 285-302, ISBN 978-953-307-851-9

Kokshenev, V.B., Silva, J.K.L. \& Garcia, G.J.M. (2003). Long-bone allometry of terrestrial mammals and the geometric-shape and elastic-force constraints of bone evolution, Journal of Theoretical Biology 224: 551-555.

Kokshenev, V.B. \& Christiansen P. (2010). Salient features in locomotion of proboscideans revealed via the differential scaling of limb long bones, Biological Journal of Linnean Society 100: 16-29.

Lovelace, D. M., Hartman, S. A. \& Wahl, W. R. (2007). Morphology of a specimen of Supersaurus (Dinosauria, Sauropoda) from the Morrison Formation of Wyoming, and a re-evaluation of diplodocid phylogen, Arquivos do Museu Nacional 65: 527-544

Marden, J.H. (2005). Scaling of maximum net force output by motors used for locomotion, Journal of Experimental Biology 208: 1653-1664.

Mazetta, G.V., Christiansen, P. \& Fariña, R.A. (2004). Giants and Bizarres: Body Size of Some Southern South American Cretaceous, Dinosaurs. Historical Biology 16: 71-83. 
McFarlan, D. (1992). The Guinness book of records. Guinness Publ. Ltd, Enfield, Middlesex.

McMahon, T.A. (1973). Size and shape in biology, Science 179: 1201-1204.

McMahon, T.A. (1975a). Using body size to understand the structural design of animals: quadrupedal locomotion, Journal of Applied Physiology 39: 619-627.

McMahon, T.A. (1975b). Allometry and biomechanics: limb bones in adult ungulates, American Naturalist 109: 547-563.

Nowak, R. (1991). Walker's mammals of the World. Johns Hopkins University Press, Baltimore.

Padian, K., Horner, J.R. \& Ricqles A. de (2004). Growth in small dinosaurs and pterosaurs: The evolution of archosaurian growth strategies, Journal of Vertebrate Paleontology 24: 555-571.

Paul, G.S. \& Christiansen, P. (2000). Forelimb posture in neoceratopsian dinosaurs: implications for gait and locomotion, Paleobiology 26: 450-465.

Prange, H.D., Anderson, J.F. \& Rahn, H. (1979). Scaling of skeletal mass to body mass in birds and mammals, American Naturalist 113: 103-122.

Rensberger, J.M. \& Watabe, M. (2000). Fine structure of bone in dinosaurs, birds and mammals, Nature 406: 619-622.

Rubin, C.T. \& Lanyon, L.E., (1982). Limb mechanics as a function of speed and gait: a study of functional stains in the radius and tibia of horse and dog. Journal of Experimental Biology: 101 187-211.

Rubin, C.T. \& Lanyon, L.E. (1984). Dynamic strain similarity in vertebrates; an alternative to allometric limb bone scaling, Journal of Theoretical Biology 107: 321-327.

Sander, M.P. (2000). Longbone histology of the Tendaguru sauropods: Implications for growth and biology, Paleobiology 26: 466-488.

Selker, F. \& Carter, D.R. (1989). Scaling of long bone fracture strength with animal mass. Journal of Biomechanics 22: 1175-1183.

Schmidt-Neielsen, K. (1984). Scaling: Why Is Animal Size So Important? Cambridge University Press, Cambridge.

Sharp, N.C.C. (1997). Timed running speed of a cheetah (Acinonyx jubatus), Journal of Zoology 241: 493-494.

Sellers, W.I. \& Manning, P.L. (2007). Estimating dinosaur maximum running speeds using evolutionary robotics, Proceedings of Royal Society B 274: 2711-2716.

Taylor, M.P. (2009). A Re-evaluation of Brachiosaurus altithorax Riggs 1903 (Dinosauria, Sauropoda) and its generic separation from Giraffatitan brancai (Janensh 1914), Journal of Vertebrate Paleontology 29: 787-806

Taylor, D., O'Reilly, P., Vallet, L. \& Lee, T.C. (2003). The fatigue strength of compact bone in torsion, Journal of Biomechanics 36: 1103-1109.

Tulborn, R.A. (1990). Dinosaur Tracks. Chapman and Hall, London.

Wilson, J.A. \& Carrano, M.T. (1999). Titanosaurs and the origin of 'wide-gauge' trackways: a biomechanical and systematic perspective on sauropod locomotion, Paleobiology 25: 252-267.

Wood, G.L. (1976). The Guinness Book of Animal Facts and Feats. Guinness Superlatives Ltd, Enfield, Middlesex. 


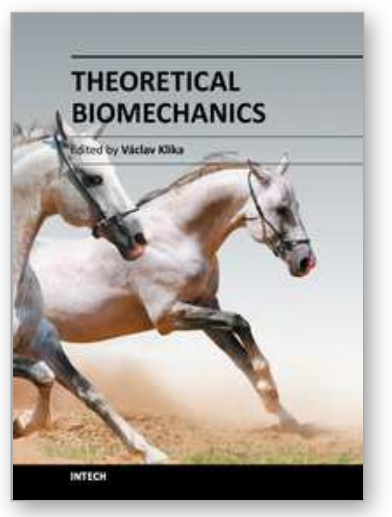

\author{
Theoretical Biomechanics \\ Edited by Dr Vaclav Klika
}

ISBN 978-953-307-851-9

Hard cover, 402 pages

Publisher InTech

Published online 25, November, 2011

Published in print edition November, 2011

During last couple of years there has been an increasing recognition that problems arising in biology or related to medicine really need a multidisciplinary approach. For this reason some special branches of both applied theoretical physics and mathematics have recently emerged such as biomechanics, mechanobiology, mathematical biology, biothermodynamics. This first section of the book, General notes on biomechanics and mechanobiology, comprises from theoretical contributions to Biomechanics often providing hypothesis or rationale for a given phenomenon that experiment or clinical study cannot provide. It deals with mechanical properties of living cells and tissues, mechanobiology of fracture healing or evolution of locomotor trends in extinct terrestrial giants. The second section, Biomechanical modelling, is devoted to the rapidly growing field of biomechanical models and modelling approaches to improve our understanding about processes in human body. The last section called Locomotion and joint biomechanics is a collection of works on description and analysis of human locomotion, joint stability and acting forces.

\title{
How to reference
}

In order to correctly reference this scholarly work, feel free to copy and paste the following:

Valery B. Kokshenev and Per Christiansen (2011). Evolution of Locomotor Trends in Extinct Terrestrial Giants Affected by Body Mass, Theoretical Biomechanics, Dr Vaclav Klika (Ed.), ISBN: 978-953-307-851-9, InTech, Available from: http://www.intechopen.com/books/theoretical-biomechanics/evolution-of-locomotor-trends-inextinct-terrestrial-giants-affected-by-body-mass

\section{INTECH}

open science | open minds

\section{InTech Europe}

University Campus STeP Ri

Slavka Krautzeka 83/A

51000 Rijeka, Croatia

Phone: +385 (51) 770447

Fax: +385 (51) 686166

www.intechopen.com

\section{InTech China}

Unit 405, Office Block, Hotel Equatorial Shanghai

No.65, Yan An Road (West), Shanghai, 200040, China

中国上海市延安西路65号上海国际贵都大饭店办公楼405单元

Phone: $+86-21-62489820$

Fax: $+86-21-62489821$ 
(C) 2011 The Author(s). Licensee IntechOpen. This is an open access article distributed under the terms of the Creative Commons Attribution 3.0 License, which permits unrestricted use, distribution, and reproduction in any medium, provided the original work is properly cited. 